Document downloaded from:

http://hdl.handle.net/10251/122867

This paper must be cited as:

López, JJ.; Payri, F.; Martín, J.; Carreño-Arango, R. (2018). Improvement and application of a methodology to perform the Global Energy Balance in internal combustion engines. Part 1: Global Energy Balance tool development and calibration. Energy. 152:666-681. https://doi.org/10.1016/j.energy.2018.03.118

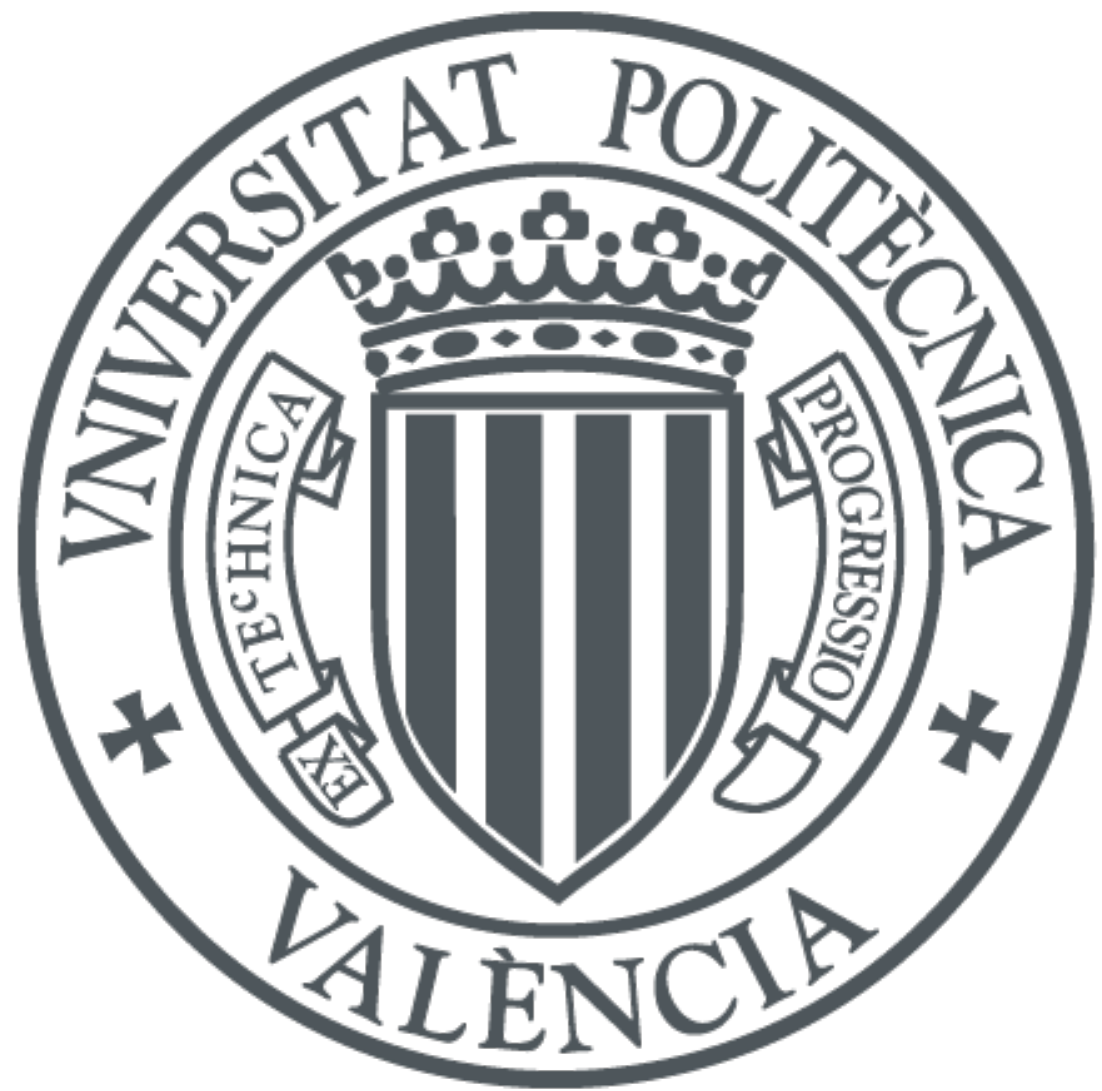

The final publication is available at

http://doi.org/10.1016/j.energy.2018.03.118

Copyright Elsevier

Additional Information 


\title{
Improvement and application of a methodology to perform the Global Energy Balance in internal combustion engines. Part 1: Global Energy Balance tool development and calibration
}

\author{
Francisco Payri, José Javier López, Jaime Martín*, Ricardo Carreño \\ CMT-Motores Térmicos, Universitat Politècnica de València, Camino de Vera s/n, 46022, Valencia, Spain
}

\begin{abstract}
The increasingly stringent internal combustion engines emissions regulations, has led to the extended use of aftertreatment systems, giving progressively more importance to the engine efficiency optimization. In this framework, the combined modelling and experimental methodologies to perform and analyse the energy balance are key to evaluate the potential of different engine strategies aimed at the consumption optimization and the identification of the improvement paths. This work has been divided into two parts, dealing separately with the development and application of a global energy balance tool. This article corresponds to the first part, which comprises the description of the models required to perform a detailed energy balance and the calibration methodologies followed to achieve accurate energy terms estimation. The models are calibrated based on experimental information, thus, a thermodynamic analysis aimed at defining comparable quantities between experimental and modelled terms is performed. The uncertainty analysis of the tool shows a deviation in the determination of the heat transfer to the coolant and the oil of about $\pm 2 \%$, and in terms of fuel energy about $\pm 1 \%$.
\end{abstract}

Keywords: Energy balance, Internal combustion engines, Heat transfer, Consumption reduction

${ }^{*}$ Corresponding author. Tel: +34963877650 ; fax: +34963877659

Email address: jaimardi@mot.upv.es (Jaime Martín)

URL: www. cmt.upv.es (Jaime Martín) 


\section{Nomenclature}

$c_{v} \quad$ Specific heat at constant volume $\ldots \ldots \ldots \ldots \ldots \ldots \ldots \ldots \ldots \ldots \ldots \ldots$

$\dot{H}_{b b} \quad$ Blow-by sensible enthalpy flow $\ldots \ldots \ldots \ldots \ldots \ldots[W],\left[\% m_{f} H v\right]$

$\dot{H}_{g} \quad$ Net sensible enthalpy flow of exhaust gases $\ldots \ldots \ldots[W],\left[\% m_{f} H v\right]$

$\dot{H}_{i c} \quad$ Incomplete combustion energy term $\ldots \ldots \ldots \ldots \ldots[W],\left[\% m_{f} H v\right]$

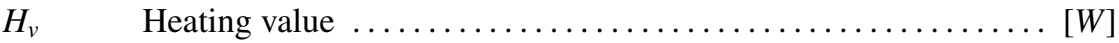

$\dot{m} \quad$ Mass flow rate $\ldots \ldots \ldots \ldots \ldots \ldots \ldots \ldots \ldots \ldots \ldots \ldots \ldots \ldots \ldots \ldots \ldots \ldots \ldots$

$N_{a} \quad$ Auxiliary power consumption $\ldots \ldots \ldots \ldots \ldots \ldots \ldots[W],\left[\% m_{f} H v\right]$

$N_{f r, b e a r} \quad$ Bearings friction losses $\ldots \ldots \ldots \ldots \ldots \ldots \ldots \ldots \ldots[W],\left[\% m_{f} H v\right]$

$N_{f r, v a l v} \quad$ Valves friction losses $\left.\ldots \ldots \ldots \ldots \ldots \ldots \ldots \ldots \ldots \ldots \ldots \ldots m_{f} H v\right]$

$N_{\text {cool }} \quad$ Coolant pump power consumption $\ldots \ldots \ldots \ldots \ldots \ldots[W],\left[\% m_{f} H v\right]$

$N_{e} \quad$ Indicated efficiency $\ldots \ldots \ldots \ldots \ldots \ldots \ldots \ldots \ldots \ldots \ldots \ldots \ldots \ldots,[\% \ldots \ldots$

$N_{\text {oil }} \quad$ Fuel pump power consumption $\ldots \ldots \ldots \ldots \ldots \ldots[W],\left[\% m_{f} H v\right]$

$N_{f r} \quad$ Friction energy losses $\ldots \ldots \ldots \ldots \ldots \ldots \ldots \ldots \ldots \ldots,\left[\% m_{f} H v\right]$

$N_{\text {oil }} \quad$ Oil pump power consumption $\ldots \ldots \ldots \ldots \ldots \ldots \ldots[W],\left[\% m_{f} H v\right]$

$N_{p} \quad$ Pumping power $\left.\ldots \ldots \ldots \ldots \ldots \ldots \ldots \ldots \ldots \ldots \ldots \ldots \ldots \ldots \ldots m_{f} H v\right]$

$N_{f r, p i s} \quad$ Piston rings friction losses $\ldots \ldots \ldots \ldots \ldots \ldots \ldots \ldots[W],\left[\% m_{f} H v\right]$

$N_{\text {turbo }} \quad$ Turbocharger power $\left.\ldots \ldots \ldots \ldots \ldots \ldots \ldots \ldots \ldots \ldots \ldots \ldots m_{f} H v\right]$

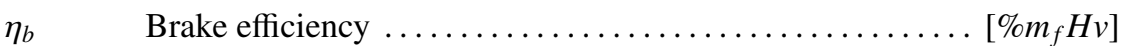

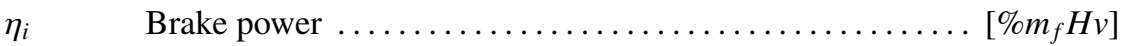

$\eta_{m} \quad$ Mechanical efficiency $\ldots \ldots \ldots \ldots \ldots \ldots \ldots \ldots \ldots \ldots \ldots \ldots \ldots \ldots \ldots \ldots$

$p \quad$ In-cylinder pressure $\ldots \ldots \ldots \ldots \ldots \ldots \ldots \ldots \ldots \ldots \ldots \ldots \ldots \ldots \ldots \ldots \ldots \ldots$

RoHR Rate of Heat Released $\ldots \ldots \ldots \ldots \ldots \ldots \ldots \ldots \ldots \ldots \ldots \ldots \ldots \ldots \ldots \ldots \ldots$

$\dot{Q}_{a} \quad$ Heat transfer in the intercooler $\ldots \ldots \ldots \ldots \ldots \ldots[W],\left[\% m_{f} H v\right]$

$\dot{Q}_{\text {cool }} \quad$ Heat transfer to the coolant $\ldots \ldots \ldots \ldots \ldots \ldots \ldots \ldots \ldots,\left[\% m_{f} H v\right]$

$\dot{Q}_{\mathrm{EGR}} \quad$ Heat transfer in the EGR cooler ............. $[W],\left[\% m_{f} H v\right]$

$\dot{Q}_{\text {ext }} \quad$ Heat transfer to the ambient $\ldots \ldots \ldots \ldots \ldots \ldots \ldots \ldots,\left[\% m_{f} H v\right]$

$\dot{Q}_{m i s c} \quad$ Miscellaneous energy term $\ldots \ldots \ldots \ldots \ldots \ldots \ldots \ldots \ldots,\left[\% m_{f} H v\right]$

$\dot{Q}_{\text {oil }} \quad$ Heat transfer to the engine body oil in the engine block $[W],\left[\% m_{f} H v\right]$

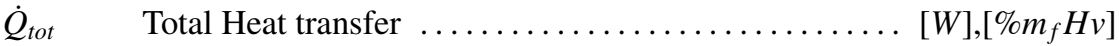

$\dot{Q}_{\text {turbo }} \quad$ Heat transfer to the turbocharger oil $\ldots \ldots \ldots \ldots \ldots \ldots[W],\left[\% m_{f} H v\right]$

$\dot{Q}_{\text {unbal }} \quad$ Unbalance energy term $\ldots \ldots \ldots \ldots \ldots \ldots \ldots \ldots \ldots \ldots \ldots,\left[\% m_{f} H v\right]$

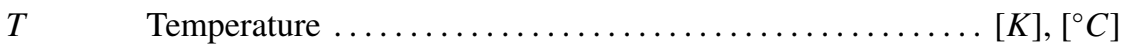

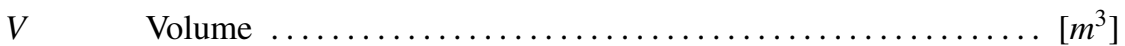




\begin{tabular}{|c|c|}
\hline \multicolumn{2}{|l|}{ Abbreviations } \\
\hline DI & Direct injection \\
\hline ECU & Engine control unit \\
\hline EGEB & External Global Energy Balance \\
\hline EGR & Exhaust Gases Recirculation \\
\hline GEB & Global Energy Balance \\
\hline HT & Heat Transfer \\
\hline ICE & Internal Combustion Engine \\
\hline IGEB & Internal Global Energy Balance \\
\hline IVC & Intake Valve Closing \\
\hline $\mathrm{PCV}$ & Pressure control valve \\
\hline RTD & Resistance Temperature Detectors \\
\hline SOI & Start Of Injection \\
\hline $\mathrm{TDC}$ & Top Dead Centre \\
\hline $\mathrm{VCV}$ & Volume control valve \\
\hline
\end{tabular}




\section{Introduction}

In spite of the stringent emissions regulations imposed in the last years and the growing use of electric and hybrid powertrains, the Internal Combustion Engine (ICE) is still the most widespread technology in the automotive sector. To comply with the regulations aimed at the reduction of the $N O_{x}, H C$ and soot emissions, in the last two decades the engine research has been mainly focused on the limitation of pollutants formation during the combustion process and the reduction of the engine tailpipe emissions [1]. The injection strategy and combustion process have an important influence to control and reduce the harmful emissions, thus several works regarding the influence of the injection strategy [2], the high injection pressure [3] and the use of multiple injections [4, 5] on performance and emissions have been carried out. With the same purpose, the effect on combustion of different air management strategies such as high boost pressure [6] and the generation of high swirl [7] and tumble ratios [8] have been also widely studied. There is a trade-off between performance and emissions that has lead the research interest to the development of alternative strategies such as the use of Exhaust Gases Recirculation (EGR) [9], variable valve timing [10], engine control systems [11] or cleaner fuels [12]. However, despite these techniques aimed at improving the in-cylinder processes, the use of after treatment systems has become a general necessity in the automotive industry [13] in order to fulfil the current, as well as the upcoming, emissions regulations. Since further reduction of emission formation during the combustion process is barely attainable, the attention has been moving to the possibilities of optimizing the thermofluid-dynamic processes in the engine to improve the fuel consumption and reduce $\mathrm{CO}_{2}$ emissions [14].

The improvement efforts have been directed to different research areas such as thermal management [15], indicated cycle optimization [16], in-cylinder heat transfer reduction [17], friction reduction by means of low viscosity oil [18] or spray coating [19], turbocharger friction reduction [20] and engine downsizing [8] among others. In order to evaluate the benefits of a specific engine strategy, performing the Global Energy Balance (GEB) shows as a useful methodology to identify the paths followed by the chemical fuel energy. The identification of the energy repartition allows determining the effect of different processes inherent to ICE operation such as cooling, lubricating, fuel injection and air management. Therefore, the cost-benefit can be evaluated, and further development and improvement alternatives can be proposed.

The GEB is carried out by means of experimental, theoretical or combined techniques, depending on the specific research objective and the level of detail required. Different works dealing with experimental GEB can be found in the literature, and are performed to assess the effect of alternative fuels [21] and fuels blends [22] on the thermal efficiency, the Heat Transfer (HT) variation by insulate the combustion chamber walls [17] or the analysis of the engine operating conditions in the energy repartition [23]. In the most general approaches, the energy balance can be performed by considering at least the brake power, the cooling losses and the exhaust gas energy; however, more detail can also be achieved by considering the coolant and oil HT separately [23], or by defining combined terms that 
accounts for energy losses with minor impact such as heat rejection to the ambient, blow-by enthalpy and unburned fuel [17].

The theoretical modelling is a useful way to predict the main energy trends and allows simulating multiple engine configurations at lower cost than an experimental installation, thus providing guidelines for further engine improvement. There are few works dealing with the complete simulation of the energy balance terms; they can be performed from different points of view that can range from performing the analysis on the combustion chamber [24], simulating the HT at different engine sub-systems [25] or focusing in specific process such as engine cooling [26]. However, the complex phenomena involved in real operation makes difficult the accurately simulation of the energy terms, and hence the engine behaviour. For this reason, some models to assess different cooling strategies [27] or the engine operation during warm-up [28] usually require validation based on experimental information. As can be seen, there is a gap of works dealing with a complete energy balance of ICE, which provides detailed energy terms and combines experimental and modelling information sources to perform a thoroughly an integral analysis. To fill this gap, this work achieves the following main objectives:

- A new methodology to perform and analyse the GEB through the combination of experimental and theoretical models is introduced. This methodology consists on a comprehensive definition of the energy balance, which includes the most relevant internal processes.

- Due to the complexity of the energy terms determination, both experimental and modelling results have to be used. The models developed in previous works are properly cited; thus, this works includes only new models and some relevant ones, which are adjusted by means of an adjustment methodology thoroughly described.

The complete work has been dividing in two parts. This first deals with the GEB sub-models development and their calibration based on experimental tests. The objective is to assure a good agreement between the experimental and modelling results, thus providing reliability to the detailed energy repartition and allowing a comprehensive combined analysis, from which an application will be presented in the second part [29].

\section{Methodology}

This work is focused, on the one hand, to the development of the GEB tool and all the sub-models required, and on the other hand, to the comprehensive description of the adjustment methodology to ensure accurate heat flows estimations. The first task consists on the definition of the energy terms to be considered, taking into account that the number of variables and the obtaining process may differ among authors [30]; thus, a description of the GEB from the authors point of view is firstly presented. The energy interactions occurring in the engine are considered from two points of view:the first one is called External Global Energy Balance (EGEB), and it corresponds to the energy flows assuming that the engine is a black box that exchanges energy with the surrounding through the brake power, 
the heat flows and the incoming and outgoing enthalpy flows, which can be experimentally determined. On the other hand, the Internal Global Energy Balance (IGEB) includes the processes which take place inside the engine, i.e. HT from the gases to the chamber, mechanical losses, auxiliary energy consumption and some HT interactions between the energy flows going through the engine, which are mostly determined by means of models. As the energy terms of the IGEB originate the terms of the EGEB, these two approaches will allow the comparison of experimental and modelling results.

To calibrate the sub-models and to evaluate the global performance of the tool, it is necessary to determine comparable HT terms between the external and internal points of view. Thus, the HT to the coolant $\left(\dot{Q}_{\text {cool }}\right)$ and the oil $\left(\dot{Q}_{o i l}\right)$ will be analysed in detail, and a total HT term $\left(\dot{Q}_{t o t}\right)$ will be defined. To achieve a better agreement between the experimental and modelled terms, all the interactions taking place in the normal engine operation are taken into account in those definitions.

As shown in Figure 1, the calibration and development of the models required is carried out at 4 steps:

- Step 1: one of the most important modelling results is the HT to the chamber walls; therefore, a complete calibration of the HT model using motoring and combustion tests is firstly performed. The process starts with a global adjustment procedure, henceforth called Engine characterization, aimed at reducing some uncertainties regarding the engine geometry (compression ratio $-C R$ - and TDC position $-\Delta \alpha_{\mathrm{TDC}}{ }^{-}$), and some sub-models fitting constants (heat transfer model coefficient $C_{w 1}$ of the Woshni-based model detailed in section 6 and the constant $k_{\text {def }}$ of a simple deformation model -see the appendix-). These uncertain parameters are adjusted with the criterion of reducing the residuals of an apparent Rate of Heat Released $(\mathrm{RoHR})$ in a sweep of engine speed at motoring conditions, considering that in motoring conditions there is not heat release. This methodology was presented in a previous work [31]. This step allows ensuring accurate in-cylinder properties calculation, being key parameters for the sub-models, specially the HT model. The process continues with the refinement of the HT model in combustion conditions. In this case, the adjustment criterion consists on reaching an apparent combustion efficiency (ACE) of $100 \%$. Note that the results of the Engine characterization and the HT model calibration have cross effects; thus, the optimal set of values is obtained through an iterative process.

- Step 2: despite most of the HT from the hot gases to the engine walls occurs in the chamber during the closed cycle, the HT to the ports during open cycle cannot be neglected, specially at the exhaust ports, considering the high temperature and velocity of the exhaust gases. Thus, a convective model to determine the HT to the ports is developed, and it is adjusted to reduce the difference between the experimental and modelled $\dot{Q}_{t o t}$. The model to estimate the HT to the exhaust ports during open cycle is calibrated taking into account that it has more weight in the GEB than the HT to the intake ports (about 90\% of the HT to ports occurs during this phase, which is about $30 \%$ of the total modelled HT). 
- Step 3: to attain a good modelling of the HT to the coolant and the oil, it is necessary to know the detailed repartition of auxiliary $\left(N_{a}\right)$ and friction $\left(N_{f r}\right)$ losses, since most of them are dissipated in the cooling and lubricating systems. Therefore, the calibration process of the mechanical losses model is described.

- Step 4: once the HT and the mechanical losses are calibrated, the experimental and modelled heat rejection to coolant and oil are evaluated separately. At this point, the only interaction that has not been yet considered is the HT between the oil and the coolant in the engine block $\left(\dot{Q}_{\text {oil,cool }}\right)$. Thus, a model accounting for $\dot{Q}_{\text {oil,cool }}$ is developed and adjusted based on the reduction of the difference between the experimental and modelled $\dot{Q}_{\text {oil }}$.

The model development and the adjustment methodology implementation results in a completely calibrated energy balance tool, suitable to obtain precise information of the engine energy terms considering different points of view, which are useful to understand and improve the energy management in ICE.

\section{Experimental setup}

Despite the methodology proposed is general and can be applied in different types of engines, the experimental work presented was carried out in a DI Diesel engine, whose main characteristics are presented in Table 1. To attain a better control of the engine operation parameters and to perform the experimental measurements, some modifications were carried out in the original engine systems. Thus, the original coolant and oil circuits were adapted to measure the heat rejection to the coolant, to the oil in the engine block and to the oil in the turbocharger independently.

The test cell includes specific instrumentation along with a control system designed for the detailed and accurate heat flows measurement. The technical characteristics of the test cell instrumentation is presented in Table 2 while the schema of the test cell is shown in Figure 2. The installation was prepared to acquire, on the one hand, the standard data required for combustion diagnosis and to perform the heat transfer, friction and auxiliary modelling, and on the other hand, the experimental information necessary to estimate the experimental energy balance terms. Thus, the incylinder pressure, some mean variables (e.g. air and fuel mass flows, temperature and pressure at intake and exhaust lines, etc.) and some liquids (oil and coolant) mass flows and temperatures were measured.

To measure the in-cylinder pressure, which is the main input for the internal processes modelling, several AVL GH13P piezo-electric transducers were installed at the glow plug hole of each cylinder. The signal provided by the piezo-electric transducer was conditioning by means of a Kistler 5011B amplifier and the digital processing was performed following the methods described in $[32,33]$. In order to ensure the accuracy of the pressure signal obtained, the pressure sensors were calibrated according to the traditional method proposed in [34].

As the presented methodology requires several experimental inputs, special attention was paid to the reduction of experimental uncertainties. On the one hand, a calibration of all the experimental equipment was performed, 
following the standard procedures, to reduce systematic errors. On the other hand, the random uncertainties depend on the devices precision and other experimental uncertainties (that cannot be controlled). In order to obtain reliable results, the repeatability of the measurements was checked, to discard that random errors distort the results. Thus, three repetitions of each operating point were measured, evaluating the repetitiveness of the measurement by means of the standard deviation.

\section{Global energy balance}

Taking into account all the energy transformations that take place in an engine, the paths followed by the different energy terms throughout the engine operation are presented in Figures 3 and 4. Note that these schemes correspond to Diesel engines, but they can be used for different engine technologies with slight modifications. For the sake of comprehension, the energy flows and interactions are represented in two different approaches. The first point of view is called External Global Energy Balance (EGEB), and it corresponds to the energy flows assuming that the engine is a black box that exchanges energy with the surrounding through the brake power, the heat flows and the incoming and outgoing enthalpy flows, which can be experimentally determined. These terms are represented outside the dashed line in Figure 4. On the other hand, the Internal Global Energy Balance (IGEB) includes the processes which take place inside the engine, i.e. HT from the gases to the chamber, mechanical losses, auxiliary energy consumption and some HT interactions between the energy flows going through the engine, which are mostly determined by means of models. These terms are represented inside the dashed line in Figure 4. Note that the energy terms of the IGEB originate the terms of the EGEB; therefore, these two approaches will allow the comparison of experimental and modelling results.

\subsection{External global energy balance}

In this analysis, the engine is assumed to be a black-box that exchanges energy with the surrounding through the brake power, heat flows and incoming and outgoing enthalpy fluxes, (terms outside of the dashed line in Figure 4). The energy flows entering the engine are the sensible enthalpies of air $\dot{m}_{a} h_{a}^{\text {sens }}$ and fuel $\dot{m}_{f} h_{f}^{\text {sens }}$, and the chemical energy of the fuel $\dot{m}_{f} H_{v}$. The main outlet energy flows are the brake power $N_{b}$, the heat flow to the coolant $\dot{Q}_{\text {cool }}$, the sensible enthalpy of the exhaust gases $\dot{m}_{\text {exh }} h_{\text {exh }}^{\text {sens,ext }}$, which is calculated at the turbine outlet (point 4 of Figure 3), the heat flow removed in the oil exchanger $\dot{Q}_{o i l}$, the HT to the turbo oil $\dot{Q}_{t u r b o}$, the heat flow in the intercooler $\dot{Q}_{a}$, the small term corresponding to the heat loss in the fuel returning line $\dot{Q}_{f}$ and the enthalpy flow due to blow-by losses $\dot{m}_{b b} h_{b b}^{\text {sens }}$. From a thermodynamic point of view, the energy terms presented in Figure 4 are coherent, but for the sake of comprehension, it is interesting to rearrange some of them to perform the detailed analysis of the energy repartition. In this sense, the first law in the case of the EGEB can be expressed as:

$$
\dot{m}_{f} H_{v}=N_{b}+\dot{Q}_{c o o l}+\dot{Q}_{o i l}+\dot{H}_{g, e x}+\dot{Q}_{a}+\dot{Q}_{t u r b o}+\dot{Q}_{f}+\dot{H}_{i c}+\dot{H}_{b b}+\dot{Q}_{e x t}+\dot{Q}_{u n b a l, e x}
$$


where $\dot{H}_{g, e x}$ is net flow of sensible enthalpy of air and fuel, determined by means of a balance between the incoming $\left(\dot{m}_{a} h_{a}^{\text {sens }}\right.$ and $\left.\dot{m}_{f} h_{f}^{\text {sens }}\right)$ and outgoing $\left(\dot{m}_{e x h} h_{\text {exh }}^{\text {sens }}\right.$ ) $)$ enthalpy flows between compressor inlet and turbine outlet (between points 1 and 4 of Figure 3), $\dot{H}_{b b}$ is the net flow of sensible enthalpy of blow-by and $\dot{Q}_{\text {unbal,ex }}$ is the unbalance term due to experimental and modelled uncertainties.

The determination of the energy terms involved in the EGEB is based on the experimental measurements of air, fuel, coolant and oil flow rates and the temperatures at the inlet and outlet of their respective coolers as presented in Figure 2. The brake power is determined by means of the engine torque and speed measurement. The most relevant terms of the EGEB have been experimentally acquired; however, some small terms have to be estimated. The HT to the ambient $\left(\dot{Q}_{e x t}\right)$ includes the heat rejection from the engine block $\left(\dot{Q}_{\text {ext }, \text { block }}\right)$, turbocharger $\left(\dot{Q}_{\text {ext }, \text { turbo }}\right)$ and exhaust ports $\left(\dot{Q}_{\text {ext,ports }}\right)$, which are estimated considering convection and radiation between them and the surroundings, assuming that the walls are at the coolant temperature. Finally, the incomplete combustion term $\dot{H}_{i c}$ is estimated with correlations based on $\mathrm{HC}, \mathrm{CO}$ and soot measurements.

For the sake of simplicity, some quantities difficult to be measured such as $\dot{Q}_{e x t}$, some terms with small relative weight such as $\dot{Q}_{t u r b o}, \dot{Q}_{f}, \dot{H}_{i c}$ and $\dot{H}_{b b}$, and the experimental unbalance $\dot{Q}_{u n b a l, e x}$ are grouped in a miscellaneous term $\dot{Q}_{\text {misc }}$ as presented in Equation (2).

$$
\dot{Q}_{m i s c}=\dot{Q}_{e x t}+\dot{Q}_{t u r b o}+\dot{Q}_{f}+\dot{H}_{i c}+\dot{H}_{b b}+\dot{Q}_{u n b a l, e x}
$$

\subsection{Internal global energy balance}

The internal analysis of the energy balance includes all the terms inside the box delimited by the dashed line of Figure 4. Contrary to the external analysis, the IGEB has to be performed through modelled terms and only a few experimental variables are required, being the most important the in-cylinder pressure. Apart from the brake power, the IGEB considers the HT from the hot gases to the combustion chamber $\dot{Q}_{c h a m}$, which is determined by means of an adapted HT model [35] based on the Woschni proposal $[36,37]$. $\dot{Q}_{\text {cham }}$ can be also split in heat transfer to piston $\left(\dot{Q}_{p i s}\right)$, liner $\left(\dot{Q}_{l i n}\right)$ and cylinder head $\left(\dot{Q}_{c h}\right)$, which are finally dissipated to the coolant $\left(\dot{Q}_{\text {cham,cool }}\right)$ and the oil $\left(\dot{Q}_{\text {cham,oil }}\right)$. To perform this detailed HT repartition, a lumped conductance model $[38,39]$ which also accounts for the wall temperature determination is used.

The internal analysis also considers the HT to the ports $\dot{Q}_{\text {ports }}$, the sensible enthalpy of the exhaust gases $\dot{m}_{e x h} h_{\text {exh }}^{\text {sens }}$ (calculated at the point 3' of Figure 3), the friction $N_{f r}$ (i.e. piston $N_{f r, p i s}$, bearings $N_{f r, b e a r}$ and valves $N_{f r, v a l v}$ ), the energy consumption of the auxiliary systems $N_{a}$ (i.e. the coolant pump $N_{\text {cool }}$, oil pump $N_{\text {oil }}$ and fuel pump $N_{f}$ ), and finally, the EGR heat losses $\dot{Q}_{\mathrm{EGR}}$. Some additional consideration about the internal processes have to be mentioned: 
- The turbocharger power $N_{\text {turbo }}$ is partially dissipated as heat rejection to the ambient $\left(\dot{Q}_{e x t, t u r b o}\right)$ and as HT in the intercooler (calculated along with $\dot{Q}_{a}$ ).

- As the HT between oil and coolant estimation $\dot{Q}_{\text {oil,cool }}$ is important to compare the external and internal HT to coolant and oil, a model for its estimation is presented later in this article.

Taking into account these comments and the internal interactions observed in Figure 4, Equation (1) can be expressed as:

$$
\begin{aligned}
\dot{m}_{f} H_{v}= & N_{b}+\left(N_{f r}+N_{a}\right)+\dot{Q}_{\text {cham }}+\dot{Q}_{\text {ports }}+\dot{Q}_{\mathrm{EGR}}+\dot{H}_{g, \text { ex }}+\dot{Q}_{a}+ \\
& +\dot{Q}_{\text {turbo }}+\dot{Q}_{\text {ext,turbo }}+\dot{Q}_{\text {ext,man }}+\dot{H}_{b b}+\dot{H}_{i c}+\dot{Q}_{\text {unbal, in }}
\end{aligned}
$$

Note that $\dot{Q}_{\text {ext,turbo }}$ and the HT from the exhaust manifold to the ambient $\left(\dot{Q}_{\text {ext,man }}\right)$ are not explicitly shown in Figure 4 because they are part of $\dot{Q}_{\text {ext }}$.

Equation (3) is consistent with the scheme presented in Figure 4; however, it is convenient to rearrange it. Taking into account the Figure 3, an internal net flow of sensible enthalpy $\left(\dot{H}_{g, i n}\right)$ is calculated between intake manifold before air and EGR mixing (point 2') and exhaust manifold after EGR extraction (point 3), which is relevant in the methodological description presented in this work, and that allows the analysis of the exhaust enthalpy losses in part 2 of this work [29]. Taking this into consideration, $\dot{H}_{g, i n}$ can be expressed as:

$$
\dot{H}_{g, \text { in }}=\dot{H}_{g, e x}+\dot{Q}_{a}+\dot{Q}_{t u r b o}+\dot{Q}_{\text {ext }, \text { turbo }}
$$

then, by replacing Equation (4) in Equation (3) and considering that $\dot{Q}_{e x t, \operatorname{man}}$ has a negligible weight, the following definition of the IGEB is obtained:

$$
\dot{m}_{f} H_{v}=N_{b}+\left(N_{f r}+N_{a}\right)+\dot{Q}_{c h a m}+\dot{Q}_{p o r t s}+\dot{H}_{g, i n}+\dot{Q}_{\mathrm{EGR}}+\dot{H}_{b b}+\dot{H}_{i c}+\dot{Q}_{\text {unbal,in }}
$$

\section{Equivalence between heat rejection terms in the internal and external analysis}

The transformation of the energy during the engine operation is a complex process, considering the relationship between the energy terms described. Moreover, the energy balance definitions in Equations (1) and (5) can also differ depending on the energy terms simplifications considered, taking into account the available experimental installation and the models used. As commented, the GEB has been defined by two different paths, one which considers the engine as a black box, whose terms are mainly experimentally determined, and the other which takes into consideration the internal energy transformations, whose terms are mainly obtained through modelling based on in-cylinder pressure. Due to the different nature of this two points of view, it is necessary to define comparable HT terms between them. Such terms helps to improve the HT modelling and analysis since they can be used for the sub-models development, fitting and validation. 


\subsection{Total heat transfer}

As will be shown in Section 6, the comparison between internal and external heat flows is important for some sub-models calibration in order to get accurate results from each engine. The first parameter to consider is the total heat transfer $\left(\dot{Q}_{t o t}\right)$, which includes all the heat rejected from the gases circulating through the engine block, including chamber and ports. In order to adjust the sub-models, the experimental $\left(\dot{Q}_{t o t, \text { exp }}\right)$ and modelled $\left(\dot{Q}_{t o t, m o d}\right)$ values of $\dot{Q}_{t o t}$ have to be defined.

In the case of $\dot{Q}_{t o t, \text { mod }}$, it corresponds to the addition of the HT to the chamber and ports as presented in Equation (6):

$$
\dot{Q}_{t o t, m o d}=\dot{Q}_{\text {cham }, \text { cool }}+\dot{Q}_{\text {ports }}+\dot{Q}_{\text {cham }, \text { oil }}
$$

Some considerations have to be done to obtain $\dot{Q}_{\text {tot,exp }}$, in order to maintaining the equivalence with the modelled term:

- The EGR is cooled with the engine coolant; therefore, the experimental $\dot{Q}_{\mathrm{EGR}}$ is subtracted from $\dot{Q}_{\text {cool }}$ to have the total heat rejected to the coolant due to HT in the block.

- The HT from gases to the chamber and ports is not completely rejected to $\dot{Q}_{c o o l}$ and $\dot{Q}_{o i l}$ since part of the energy is lost to the ambient; thus, $\dot{Q}_{\text {ext }, \text { block }}$ has to be also included in $\dot{Q}_{\text {tot,exp }}$. Note that the terms $\dot{Q}_{\text {ext,turbo }}$ and $\dot{Q}_{\text {ext,man }}$ have not been included in $\dot{Q}_{t o t, \exp }$ in order to keep the coherence with the terms included in $\dot{Q}_{t o t, m o d}$, which only includes HT in the engine block.

- The $N_{a}+N_{f r}$ term is mainly dissipated in $\dot{Q}_{\text {cool }}$ and $\dot{Q}_{o i l}$; thus, this term should be subtracted from $\dot{Q}_{t o t, \text { exp }}$. It is important to underline that $N_{f}$ (included in $N_{a}$ ) is not dissipated in the coolant nor the oil and it must not be subtracted from $\dot{Q}_{t o t, e x p}$.

Taking these comments into consideration, Equation (7) is obtained:

$$
\dot{Q}_{\text {tot }, \text { exp }}=\left(\dot{Q}_{\text {cool }}-\dot{Q}_{\mathrm{EGR}}\right)+\dot{Q}_{\text {oil }}+\dot{Q}_{\text {ext }, \text { block }}-\left(N_{a}+N_{f r}\right)+N_{f}
$$

All the energy terms presented in Equation (6) and (7) are known from models or experimental data except $\dot{Q}_{e x t, b l o c k}$, which can be determined by means of subtraction between the total energy $\dot{m}_{f} H_{v}$ and the addition of all the GEB terms in Equation (1), as presented in Equation (8).

$$
\begin{aligned}
\dot{Q}_{e x t} & =\dot{Q}_{e x t, b l o c k}+\dot{Q}_{e x t, t u r b o}+\dot{Q}_{e x t, \text { man }} \\
& =\dot{m}_{f} H_{v}-\dot{Q}_{a}-\dot{Q}_{\text {cool }}-\dot{Q}_{\text {oil }}-\dot{Q}_{t u r b o}-N_{b}-\dot{Q}_{f}-\dot{H}_{g, e x}-\dot{H}_{b b}-\dot{H}_{i c}-\dot{Q}_{\text {unbal }, \text { exp }}
\end{aligned}
$$


The net flow of sensible enthalpy can be calculated at the ports conditions $\left(\dot{H}_{g, p o r t s}\right)$, that is between points 2" and 3' of Figure 3, thus obtaining the following expression:

$$
\dot{H}_{g, p o r t s}=\dot{H}_{g, e x}+\dot{Q}_{a}+\dot{Q}_{\mathrm{EGR}}+\dot{Q}_{t u r b o}+\dot{Q}_{e x t, t u r b o}+\dot{Q}_{e x t, m a n}
$$

and through the combination of Equations(8) and (9), $\dot{Q}_{\text {ext,block }}$ can be expressed as:

$$
\dot{Q}_{\text {ext }, \text { block }}=\dot{m}_{f} H_{v}-\dot{Q}_{\text {cool }}-\dot{Q}_{\text {oil }}-\dot{Q}_{t u r b o}-N_{b}+\dot{Q}_{\mathrm{EGR}}-\dot{Q}_{f}-\dot{H}_{g, \text { ports }}-\dot{H}_{b b}-\dot{H}_{i c}-\dot{Q}_{\text {unbal } \text { exp }}
$$

It is reasonable to assume that $\dot{Q}_{f} \approx N_{f}$ considering that, on the one hand, an important part (about $40 \%$ ) of the pumped fuel is returned and cooled, and on the other hand, the small weight of this term (lower than $1 \% \dot{m}_{f} H_{v}$ in all the cases) makes its uncertainty negligible. Taking into account this comment and replacing $\dot{Q}_{\text {ext }, \text { block }}$ of Equation (10) in Equation (7), the following expression for $\dot{Q}_{t o t, e x p}$ is obtained:

$$
\dot{Q}_{t o t, e x p}=\dot{m}_{f} H_{v}-N_{b}-\dot{H}_{g, p o r t s}-\left(N_{a}+N_{f r}\right)-\dot{H}_{b b}-\dot{H}_{i c}-\dot{Q}_{\text {unbal,exp }}
$$

This last expression is more convenient than Equation (7), since all the terms involved are experimentally acquired, and the most important of them (i.e. $\dot{m}_{f} H_{v}, N_{b}$ and $\dot{H}_{g, p o r t s}$ ) have lower experimental uncertainty than $\dot{Q}_{c o o l}$ and $\dot{Q}_{o i l}$ because of the small temperature increase of coolant and oil in the engine. Once both, $\dot{Q}_{t o t, m o d}$ and $\dot{Q}_{t o t, e x p}$ are defined, it is interesting to consider:

- All the terms conforming $\dot{Q}_{t o t, \text { mod }}$ in Equation (6) are obtained through modelling.

- All the terms conforming $\dot{Q}_{\text {tot,exp }}$ in Equation (11) are experimentally obtained.

- $\dot{Q}_{\text {tot,mod }}$ and $\dot{Q}_{\text {tot,exp }}$ are equivalent. Hence, taking into account that the experimental equipment have been properly calibrated, and all the terms were carefully measured, the good agreement between these terms is an indicator of the gas HT model performance.

\subsection{Heat transfer to coolant}

The total HT presented in previous section is an interesting parameter to assess the global consistency of the HT models, based on some experimental measurements. However, to characterize the internal thermal behaviour of an engine, it is also interesting to compare the specific repartition of the HT to coolant and oil. As for the total HT, the coolant HT can be obtained from modelled or experimental sources, but some hypothesis have to be assumed:

- All the HT to the ports is assumed to be dissipated into the coolant $\left(\dot{Q}_{p o r t s}\right)$.

- It is assumed that the piston friction $\left(N_{f r, p i s}\right)$ is dissipated into the coolant. This can be justified considering that most of the piston assembly friction takes place in the rings, thus heating both, the liner and the rings. 
Moreover, the liner temperature is much cooler than that of the piston nodes in contact with the rings $\left(90-150^{\circ} \mathrm{C}\right.$ vs $110-250^{\circ} \mathrm{C}$ ), thus having a higher temperature drop and hence higher conductive HT.

- The work of the coolant pump $\left(N_{\text {cool }}\right)$ increases the coolant enthalpy and is dissipated as fluid friction, thus slightly increasing its temperature. As a consequence, it is rejected in the coolant cooler.

- There is some HT between the oil and coolant $\left(\dot{Q}_{\text {oil,cool }}\right)$ since they circulate through the engine block and cylinder head, thus leading to some convective HT between them and the gallery walls. This heat is transferred by conduction through the walls between coolant or oil circuits. Thus, it can be stated that the engine block works as a heat exchanger between them. For convenience, it is assumed that this term is positive when it goes from oil to coolant, since in most of the cases the oil temperature is higher than that of the coolant.

- Part of the HT from chamber to coolant goes through the engine body to the engine surface, being there finally lost to the ambient by convection.

Considering these comments, the modelled HT to the coolant $\left(\dot{Q}_{\text {cool,mod }}\right)$ is defined as presented in Equation (12):

$$
\dot{Q}_{\text {cool,mod }}=\dot{Q}_{\text {cham }, \text { cool }}+\dot{Q}_{\text {ports }}+N_{f r, p i s}+N_{\text {cool }}+\dot{Q}_{\text {oil,cool }}-\dot{Q}_{\text {ext }, \text { block }}
$$

In the experimental case, the HT to the coolant is directly measured in the coolant cooler. As explained earlier, the EGR is cooled with the engine coolant; thus, in order to maintain the equivalence between terms, $\dot{Q}_{\text {EGR }}$ is subtracted from $\dot{Q}_{\text {cool }}$ as follows:

$$
\dot{Q}_{\text {cool }, \exp }=\dot{Q}_{\text {cool }}-\dot{Q}_{\mathrm{EGR}}
$$

If experimental uncertainties are controlled and the model works properly, $\dot{Q}_{\text {cool,exp }}$ and $\dot{Q}_{\text {cool,mod }}$ must show good agreement.

\subsection{Heat transfer to oil}

Similarly as for the HT to the coolant, some hypotheses have to be made to determine the modelled HT to the oil:

- The friction of the bearings $\left(N_{f r, b e a r}\right)$ and camshaft $\left(N_{v a l v}\right)$ is finally dissipated into the oil.

- The work of the oil pump $\left(N_{\text {oil }}\right)$ increases the oil enthalpy and is dissipated as friction into the fluid, thus slightly increasing its temperature. As a consequence, it is rejected in the oil cooler.

- The energy lost as HT from oil to coolant $\left(\dot{Q}_{\text {oil,cool }}\right)$ has to be considered with negative sign, as it produces a reduction of the oil circuit energy. 
Considering these hypotheses, the modelled HT to the oil $\left(\dot{Q}_{\text {oil,mod }}\right)$ is defined as presented in Equation (14):

$$
\dot{Q}_{\text {oil, } \text { mod }}=\dot{Q}_{\text {cham }, \text { oil }}+N_{f r, \text { bear }}+N_{f r, \text { alv }}+N_{\text {oil }}-\dot{Q}_{\text {oil, cool }}
$$

In the experimental case, the HT to the oil $\left(\dot{Q}_{\text {oil,exp }}\right)$ is directly measured in the oil heat exchanger and no further assumptions are necessary:

$$
\dot{Q}_{\text {oil } \exp } \equiv \dot{Q}_{\text {oil }}
$$

As for the coolant, $\dot{Q}_{o i l, \text { exp }}$ and $\dot{Q}_{\text {oil,mod }}$ must have similar values when the experimental uncertainties are controlled and a proper modelling work is done.

\section{IGEB model development and calibration}

To perform the IGEB, the model to estimate the HT to chamber has been comprehensively calibrated, and some specific sub-models have been developed: HT to the ports, mechanical losses and HT from oil to coolant. For all cases, the calibration methodology is described in the following sections.

\subsection{Chamber heat transfer model adjustment}

As shown in Figure 1, the step 1 consists on the calibration of the HT to the chamber in motoring and combustion conditions. The model used to calculates the HT to the chamber is based on the well known Woschni model $[36,37]$ with some modifications regarding the swirl instantaneous evolution [35]. In Equation (16), the model to estimate the heat transfer coefficient $h$ is presented:

$$
h=C D^{b-1} p^{b} T^{0.75-1.62 b}\left[C_{w 1} c_{m}+C_{w 2} c_{u}+C_{2} \frac{V_{d} p_{\mathrm{IVC}}}{V_{\mathrm{IVC}} T_{\mathrm{IVC}}}\left(p-p_{0}\right)\right]^{b}
$$

where $D$ is the cylinder bore, $p$ is the in-cylinder pressure, $T$ is the gas temperature, $c_{m}$ is the mean piston speed, $c_{u}$ is the instantaneous swirl speed, $V_{d}$ is the displaced volume, $p_{\mathrm{IVC}}, T_{\mathrm{IVC}}$ and $V_{\mathrm{IVC}}$ are the pressure, temperature and volume at $I V C$ respectively, $p_{0}$ is the motoring pressure assuming a polytropic evolution, $C=0.012$ and $b=0.7$ are constant values and $C_{w 1}, C_{w 2}=C_{w 1} / 1.7$ and $C_{2}$ are model fitting constants [40]. In motoring conditions $p=p_{0}$, therefore the last term of Equation (16), which accounts for the gas velocity variation due to combustion is equal to zero, thus obtaining the following expression:

$$
h=C D^{b-1} p^{b} T^{0.75-1.62 b}\left[C_{w 1} c_{m}+C_{w 2} c_{u}\right]^{b}
$$

In motoring conditions the RoHR is zero; however, the expression to calculate it, Equation (18), can provide a non-zero value $\left(\varepsilon^{R o H R}\right)$ due to the engine-installation and experimental uncertainties. 


$$
\varepsilon^{R o H R}=m c_{v} d T+d Q+p d V+R T d m_{b b}
$$

The calibration of the HT to chamber walls is performed in a two stages process as presented in Figure 5. The $1^{\text {th }}$ stage consist on the Engine characterization in the speed swept at motoring conditions shown in Table $3 a$. The methodology consists on the reduction of $\varepsilon^{R O H R}$ through the determination of an optimal set of values for the main uncertainties affecting the HT (CR, $\Delta \alpha_{\mathrm{TDC}}$ and $\left.k_{d e f}\right)$, which are obtained along with the HT calibration constant $\left(C_{w 1}\right)$. The complete description of the adjustment methodology is presented in detail in a previous work [31]. From this step, a set of values for the stated uncertainties are obtained, which are valid for motoring conditions; however, the HT shows an important variation between motoring and combustion conditions due to the higher temperature and the different fluid dynamics caused by the spray. To ensure the accuracy, different calibration constants are defined to be used either in motoring $\left(C_{w 1, m}\right)$ or combustion $\left(C_{w 1, c}\right)$ conditions respectively.

To get the $C_{w 1, c}$ value, the $\mathbf{2}^{\text {nd }}$ stage consists on the calibration procedure with combustion test, in which the Woschni constants $\left(C_{w 1, c}\right.$ and $C_{2}$ of Equation (16)) are determined with the criterion of the Apparent Combustion Efficiency optimization $\left(A C E=\frac{H R_{\max }}{\dot{m}_{f} H_{v}}\right.$, where $H R_{\max }$ is the maximum cumulative heat released [31]), which should equals the combustion efficiency, that is $\approx 100 \%$ in conventional Diesel combustion.

The results of the Engine characterization and the HT calibration are presented in Table 4. In Figure 6, the ACE for the complete engine map before and after the adjustment is presented. It is possible to see that the $A C E$ was at first overestimated for almost all the measured points, which implies a prior overestimation of the HT to the coolant and oil

\subsection{Heat transfer to the ports}

Once the HT to chamber model has been thoroughly calibrated, the step 2 shown in Figure 1 consists on developing and calibrating a HT model to the ports. The HT from gases to the ports is mainly due to convection, where the heat transfer coefficient is calculated by means of a non-dimensional analysis as a function of the Nusselt $N_{u}$, Reynolds $R_{e}$ and Prandtl $\operatorname{Pr}$ numbers as follows:

$$
N_{u}=a R_{e}^{m 1} P_{r}^{m 2}
$$

where $a, m 1$ and $m 2$ are constant values. Since the thermodynamic conditions at intake and exhaust ports are very different, the definitions and simplifications of the Equation (19) to calculate $h$ are stated considering the specific thermo-fluid-dynamic characteristics of each of them. The most simple case is the intake port, where the temperature difference between the air and the coolant is almost constant during the entire cycle and the energy exchange is small in comparison with the rest of the energy terms; therefore, it is averaged calculated based on the proposal of Depcik [41], as shown in Equation (20): 


$$
\bar{N}_{u}=0.0694 \bar{R}_{e}^{0.75}
$$

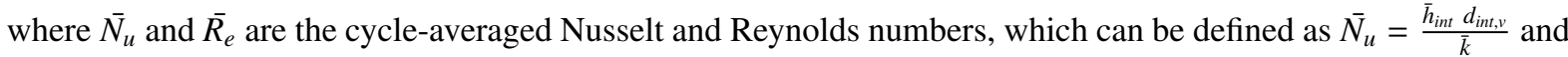
$\bar{R}_{e}=\frac{d_{i n t, v} \bar{\nu} \bar{\rho}}{\bar{\mu}}$, being $d_{i n t, v}$ the inlet valve diameter, and $\bar{h}_{i n t}, \bar{k}, \bar{v}, \bar{\rho}$ and $\bar{\mu}$ the cycle-averaged heat transfer coefficient, conductivity, velocity, density and viscosity of the gas respectively. Solving for $\bar{h}$, the Equation (21) is obtained:

$$
\bar{h}_{\text {int }}=0.0694 \bar{k} d_{i n t, v}^{-1.75}\left[\frac{4\left(\dot{m}_{a}+\dot{m}_{\mathrm{EGR}}\right)}{z \bar{\mu} N_{\text {int,v }} \pi}\right]^{0.75}
$$

where $\dot{m}_{a}$ and $\dot{m}_{\mathrm{EGR}}$ are the intake air and EGR flow rates, $N_{i n t, v}$ is the number of intake valves per cylinder and $z$ is the number of cylinders.

In the case of the exhaust ports, the heat transfer coefficient expression is different during the closed cycle and the open cycle. This is justified since in the open cycle the thermo-fluid-dynamics significantly differs from those of the closed cycle, mainly due to the high gas velocity and temperature when the valve is open, which lies in higher heat transfer coefficient and transient thermal conditions. Similarly as for the intake ports, the heat transfer coefficient in the closed cycle $\left(\bar{h}_{e x h, c c}\right)$ is estimated from a non-dimensional analysis, resulting in the following expression [42]:

$$
\bar{h}_{e x h, c c}=0.022 \bar{k} d_{e x h, v}^{-1.8}\left[\frac{4\left(\dot{m}_{a}+\dot{m}_{\mathrm{EGR}}+\dot{m}_{f}\right)}{z \bar{\mu} N_{e x h, v} \pi}\right]^{0.8}
$$

The instantaneous HT in the exhaust port at open cycle is estimated based on a non-dimensional analysis and the Sieder and Tate proposal [43] as follows:

$$
h_{e x h, c a}=a\left(R_{e}\right)^{0.6} \operatorname{Pr}\left(\frac{\mu}{\mu_{p}}\right)^{0.14} \frac{k}{d_{e x h, v}}
$$

where $h_{e x h, c a}$ is the instantaneous heat transfer coefficient in the exhaust during the open cycle, $a$ is a constant value, $\mu_{p}$ and $\mu$ are the viscosity of the gas at the ports wall and gas mean temperatures, $R_{e}$ and $P_{r}$ are the instantaneous Reynolds and Prandtl numbers, and the relation $\left(\mu / \mu_{p}\right)^{0.14}$ accounts for the viscosity gradient of the gases at each crank angle, due to the gas and wall temperature difference.

As presented in Table 5, the HT to the exhaust ports during the open cycle accounts for more than $90 \%$ of the total HT to the ports. Thus, taking into account that the HT to the chamber walls was previously adjusted, the HT to the exhaust ports during the open cycle is the only term affecting $\dot{Q}_{t o t, \text { mod }}$. Therefore, the calibration of the $a$ constant in Equation (23) is performed with the criterion of the difference minimization between $\dot{Q}_{t o t, e x p}$ and $\dot{Q}_{t o t, m o d}$. In Figure 11 it is possible to see the comparison of the experimental and modelled total HT for an adjusted value of $a=1.63$. 


\subsection{Mechanical losses}

To attain a proper repartition of the HT to coolant and oil, the detailed friction and auxiliary contributions are required; therefore, a friction and auxiliary losses model has to be developed and calibrated as shown in the step $\mathbf{3}$ of Figure 1.

Friction between piston pack and liner: the friction between piston pack and liner depends on the lubrication regime, which is determined through the duty parameter $\left(S_{r i}\right)$, determined as presented in Equation (24)[44]:

$$
S_{r i}(\alpha)=\frac{\pi D \mu v_{p i s}(\alpha)}{F_{N, r i}(\alpha)}
$$

where $v_{p i s}$ is the instantaneous piston speed, $F_{N, r i}$ is the load in the ring, $D$ is the engine bore and $\mu$ is the oil viscosity.

The friction coefficient of each ring $\left(f_{r i}\right)$ in hydrodynamic conditions was calculated as:

$$
\operatorname{Ln}\left(f_{r i}(\alpha)\right)=0.625 \operatorname{Ln}\left(S_{r i}(\alpha)\right)+1.962
$$

and in the mixed region as:

$$
f_{r i}(\alpha)=f_{0}\left(1-\frac{\left|S_{r i}(\alpha)\right|}{S_{c r}}\right)+f_{c r}\left(\frac{\left|S_{r i}(\alpha)\right|}{S_{c r}}\right)
$$

where $S_{c r}=1 \times 10^{-4}$ is the critical duty parameter, $f_{c r}=0.0225$ is the friction coefficient when $S_{r i}=S_{c r}$, and $f_{0}=0.14$ is the dry friction coefficient.

The friction between skirt and liner is calculated as a function of the duty parameter of the skirt $\left(S_{s}\right)$ as:

$$
f_{s}(\alpha)=2.5 \sqrt{S_{s}(\alpha)}
$$

The total power lost by friction in the piston pack during one cycle $\left(N_{f r}, p i s\right)$ is determined as:

$$
N_{f r, p i s}=k_{p i s}\left[\oint F_{f r, s}(\alpha) v_{p i s}(\alpha) \mathrm{d} \alpha+\sum_{r i=1}^{3} \oint F_{f r, r i}(\alpha) v_{p i s}(\alpha) \mathrm{d} \alpha\right]
$$

where the $F_{f r, r i}=f_{r i} F_{N, r i}$ and $F_{f r, s}=f_{s} F_{N, s}$ are the friction force in the rings and skirt respectively and $k_{p i s}$ is a calibration constant.

Bearings friction: according to [45], the friction force in the bearings $\left(F_{f r, b e a r}\right)$ can be determined as:

$$
F_{\text {fr,bear }}=\frac{2 \pi \mu D_{\text {bear }}^{2} \omega L_{\text {bear }}}{c \sqrt{1-\epsilon^{2}}}+\frac{c \epsilon F_{\text {bear }}}{D_{\text {bear }}} \sin \varphi
$$


where $\omega$ is the bearings angular speed, $D_{\text {bear }}$ is the bearing diameter, $L_{\text {bear }}$ is the bearing length, $\mu$ is the oil viscosity, $c$ is the clearance between journal and bearing, $\epsilon=e / c$ is the ration between bearing eccentricity $(e)$ and clearance (c), $v_{0}$ is the speed of the bearing centre displacement and $\varphi$ is the angle between the force vector and the centres line. Details of the determination of those parameters can be found in reference [44].

Once the friction components presented in Equation (29) are determined, the power lost by friction in the bearings during one cycle can be calculated as:

$$
N_{f r, \text { bear }}=k_{\text {bear }} \sum_{i=1}^{N B}\left[\oint \frac{\omega D_{\text {bear }, i}}{2} F_{f r, b e a r, i}(\alpha) \mathrm{d} \alpha\right]
$$

where $i$ is the analysed bearing, $N B$ is the total number of bearings and $k_{\text {bear }}$ is a calibration constant.

Friction in the cam/follower contact: as the cam/tappet contact accounts for more than $85 \%$ of the total friction in the valvetrain system [46], in this work is assumed that all the friction is occurring there. The friction in the cam/follower contact $\left(F_{f r, v a l v}\right)$ has two components: the boundary friction $\left(F_{b, v a l v}\right)$ due to the asperity contact, and the viscous friction component $\left(F_{v, v a l v}\right)$ due to the shear of lubricant $[47,48]$ :

$$
F_{f r \text { valv }}=F_{b, \text { val }}+F_{v, \text { valv }}
$$

To determine the oil film thickens, key for the friction determination, the elastohydrodynamic theory can be used. For the sake of brevity, the calculation process is not included in this work. A complete description of the determination of those forces can be found in references [44, 48, 49]. In Equation (32), the final expression used to determine the total friction in the valve train $\left(N_{f r, v a l v}\right)$ is presented:

$$
N_{f r, v a l v}=k_{v a l v}\left[N_{I V} \oint F_{f r, v a l v}^{i n t}(\alpha) v_{c}^{i n t}(\alpha) \mathrm{d} \alpha+N_{E V} \oint F_{f r, v a l v}^{e x h}(\alpha) v_{c}^{e x h}(\alpha) \mathrm{d} \alpha\right]
$$

where the index int and exh refers to intake and exhaust, $v_{c}$ is the contact speed (determined as shown in reference [48]), $N_{I V}$ and $N_{E V}$ are the total number of intake and exhaust valves and $k_{v a l v}$ is the calibration constant.

Coolant pump: the coolant is pumped by means of a centrifugal pump whose rate flow depends on the rotating speed, the efficiency and the pressure drop in the cooling line. Then, the power consumption of the coolant pump can be estimated as:

$$
N_{\text {cool }}=\frac{\Delta p_{\text {cool }} \dot{V}_{\text {cool }}}{\eta_{\text {cool }}}
$$

being $\Delta p_{\text {cool }}=k 1_{\text {cool }} \dot{V}_{\text {cool }}^{2}$ the pressure drop in the cooling line, $\dot{V}_{\text {cool }}=k 2_{\text {cool }} n$ the volumetric coolant flow and $\eta_{\text {cool }}$ the pump efficiency. $k 1_{\text {cool }}$ and $k 2_{\text {cool }}$ are fitting constants obtained from manufacturers data, whose values are 
summarized in Table 6.

Oil pump: the volumetric oil pump power consumption depends on the oil pressure drop in the line $\Delta p_{\text {oil }}$, the volumetric oil flow $\dot{V}_{o i l}$ and the pump efficiency $\eta_{o i l}$ :

$$
N_{o i l}=\frac{\Delta p_{o i l} \dot{V}_{\text {oil }}}{\eta_{\text {oil }}}
$$

where $\Delta p_{\text {oil }}$ is experimentally measured and the volumetric flow is assumed to be proportional to the engine speed $\dot{V}_{\text {oil }}=k_{\text {oil }} n$, being $k_{\text {oil }}$ the proportionality constant between $\dot{V}_{\text {oil }}$ and $n$. As for the coolant pump, the constants were also calculated from manufacturers data and the values are presented in Table 6.

Fuel pump: the studied engine has a common rail system in which the fuel pump includes both, a pressure control valve (PCV) and a volume control valve ( $\mathrm{VCV}$ ), hence its behaviour differs from conventional piston pumps, in which the total amount of fuel compressed in the piston (part of which is injected and part is returned through the low pressure fuel line) mainly depends on the pump angular speed and the pump size. However, a previous analysis of the injection system showed that the total fuel mass flow variation at different engine speeds is limited, and there is also a load effect due to the ECU strategy, which controls the VCV and hence the fuel pump power consumption.

The experimental calibration performed consisted on a swept of speed and rail pressure in the motoring test conditions presented in Table $3 a$, in which the injectors were replaced by dummy's and the fuel flow was by-passed. To provide generality to the model, an empirical correlation (Equation (35)) as function of the injected fuel mass $m_{f}$, the rail pressure $p_{\text {rail }}$ and the fuel pump efficiency $\eta_{f}$ is presented. Some calibration constants $\left(k 1_{f}\right.$ and $\left.k 2_{f}\right)$, whose values are summarized in Table 6 are used to fit the model.

$$
N_{f}=\frac{k 1_{f} m_{f}^{k 2_{f}} p_{\text {rail }}}{\eta_{f}}
$$

Friction models calibration: a linear correlation for the piston friction constant $k_{p i s}=k 1_{p i s}+k 2_{p i s} n$ was included to improve the model performance. Similar approaches have also been reported by other authors [50]. The remaining parameters, $k_{\text {bear }}$ and $k_{\text {valv }}$ were kept constant. The model is adjusted in the engine map, taking as reference the experimental auxiliary and friction term $\left(N_{a}+N_{f r}\right)_{\text {exp }}$, obtained from the indicated $N_{i}$, the pumping $N_{p}$ and the brake power $N_{b}$, as presented in Equation (36).

$$
\left(N_{a}+N_{f r}\right)_{\exp }=N_{i}+N_{p}-N_{b}
$$

The calibration is performed with the criterion of the difference reduction between the $\left(N_{a}+N_{f r}\right)_{\exp }$ and $\left(N_{a}+\right.$ $\left.N_{f r}\right)_{\text {mod }}$, being $\left(N_{a}+N_{f r}\right)_{\text {mod }}=N_{\text {cool }}+N_{\text {oil }}+N_{f}+N_{f r, p i s}+N_{f r, b e a r}+N_{f r, v a l v}$. The resulting fitting constants are 
summarized in Table 6.

Figure 8 shows the mechanical losses repartition in the engine map. In the upper Figure 8, it is possible to see the good adjustment between the experimental and modelled mechanical losses, having a good behaviour for all the operating points. In the bottom Figure 8, it is possible to see the well agreement of the mechanical losses relative distribution when compared with that found in the literature [30, 44, 51], being $N_{f r, p i s}$ between $60-40 \%, N_{f r, b e a r}$ between $15-25 \%, N_{f r, v a l}$ between 5 and $15 \%, N_{\text {cool }}$ around $15 \%, N_{\text {oil }}$ around $5 \%$ and $N_{f}$ around $20 \%$ of the total $N_{a}+N_{f r}$.

\subsection{Heat transfer from oil to coolant model}

The final step consist on the development and adjustment of a model to determine the heat transfer between oil and coolant, as shown in step 4 of Figure 1. A simple model which considers the thermal resistance between the oil and the coolant through the internal engine walls is presented in Equation (37):

$$
\dot{Q}_{\text {oil }, \text { cool }}=\frac{T_{\text {oil }}-T_{\text {cool }}}{R_{\text {oil }}+R_{\text {cond }}+R_{\text {cool }}}
$$

being $R_{\text {oil }}=1 / \bar{h}_{\text {oil }} A, R_{\text {cond }}=e / K A$ and $R_{\text {cool }}=1 / \bar{h}_{\text {cool }} A$ the thermal resistance of the oil, the engine material and the coolant, $A$ the heat transfer area, $e$ the wall thickness, $\bar{h}_{\text {oil }}$ the oil mean heat transfer coefficient, $K$ the thermal conductivity of the engine (block and cylinder head) and $\bar{h}_{\text {cool }}$ the heat transfer conductivity of the coolant. Due to the complex design of the engine cooling and lubricating systems, most of the information necessary to solve the Equation (37) is usually not available, therefore some hypothesis are assumed in the model:

- As the actual values of $\bar{h}_{\text {oil }}$ and $\bar{h}_{\text {cool }}$ are difficult to determine, an equivalent heat transfer coefficient proportional to the engine speed is defined as $\bar{h}=k_{1}^{\prime} n$.

- The thickness is proportional to the cylinder bore as $e=k_{2}^{\prime} D$.

- The HT area is proportional to the cylinder bore as $A=k_{3}^{\prime} D^{2}$.

Rearranging Equation (37) with the hypothesis assumed, the following expression is obtained:

$$
\dot{Q}_{\text {oil }, \text { cool }}=\frac{T_{\text {oil }}-T_{\text {cool }}}{\frac{2}{k_{1}^{\prime} n k_{3}^{\prime} D^{2}}+\frac{k_{2}^{\prime} D}{k_{3}^{\prime} D^{2} K}}=\frac{D^{2}\left(T_{\text {oil }}-T_{\text {cool }}\right)}{\frac{2}{k 1 n}+\frac{D}{k_{2} K}}
$$

where $2 / k_{1} n$ is an equivalent convection resistance and $D / k_{2} K$ is an equivalent conduction resistance, and the constants $k_{1}=6,42\left(\frac{\mathrm{W}}{\mathrm{m}^{2} \mathrm{~K} \mathrm{rpm}}\right)$ and $k_{2}=8,8 \times 10^{8}$ are the calibration constants, whose values were adjusted with the criterion of $\dot{Q}_{\text {oil,exp }}$ and $\dot{Q}_{\text {oil,mod }}$ difference minimization in the complete engine map, taking into account that $\dot{Q}_{\text {oil,cool }}$ has higher relative effect on $\dot{Q}_{\text {oil }}$ than in $\dot{Q}_{c o o l}\left(\dot{Q}_{\text {oil }}\right.$ is about 4 times lower than $\left.\dot{Q}_{c o o l}\right)$. It is possible to notice that 
$D / k_{2} K \approx 0$, which means that the conduction is negligible in comparison with the convection.

In Figure 9, the comparison between $\dot{Q}_{o i l, e x p}$ and $\dot{Q}_{o i l, m o d}$ is presented. It is possible to see that, if not HT from oil to coolant is considered, the HT to the oil is overestimated, specially at high power. Lower power operating points has not been presented in the graph because the oil cooling system was deactivated due to the low oil temperature.

Note that the accurate determination of $\dot{Q}_{\text {oil,cool }}$ would require 3D modelling. $\dot{Q}_{\text {oil,cool }}$ is a minor term of the GEB, and its main effect is observed in $\dot{Q}_{\text {oil,mod }}$ (which is also a small quantity). Therefore, the results obtained with this model are considered enough for the presented application, improving the results and the analysis of minor terms. Despite the simplicity of the model, it can be adjusted for each engine by means of the experimental HT to oil, thus more accurate results can be obtained.

\subsection{GEB tool evaluation}

As presented in Figure 7 the results of the modelled and experimental total HT after calibration are in good agreement, which ensure the global good behaviour of the tool. In Figure 9 and Figure 10, it is possible to see that the modelled HT to the oil and the coolant are also in good agreement with the experimental results. These results demonstrate the method reliability regarding the total HT estimation as well as the internal repartition.

From Figure 11 to Figure 13 the relative difference between the total HT, the HT to the coolant and the HT to the oil estimation in terms of the fuel energy $\left(\% \dot{m}_{f} H_{v}\right)$ are presented. The maximum difference between $\dot{Q}_{t o t, m o d}$ and $\dot{Q}_{t o t, \text { exp }}$ lies between -2 and $-10 \% \dot{m}_{f} H_{v}$ at low engine speed, this is explained by the high experimental uncertainty at those operating conditions. However, in the rest of the map the difference is clearly lower, depicting an average difference lower than $\pm 1 \% \dot{m}_{f} H_{v}$. The HT to the coolant has a maximum uncertainty about $\pm 5 \% \dot{m}_{f} H_{v}$ at $1000 \mathrm{rpm}$ and $25 \%$ load; however, in the engine map the average differences are about $\pm 2 \% \dot{m}_{f} H_{v}$. Finally, the HT to the oil has the lower relative difference in the complete engine map, showing its maximum deviation of $-1.5 \%_{m_{f}} H_{v}$ at low speed and load.

As can be seen, thanks to the improvements made in the sub-models and the calibration methodologies described, the potential and good performance of the GEB tool has been demonstrated, being now ready to be used for the comprehensive analysis of the energy balance. In the second part of this work, the application of the GEB in the calibrated engine is presented.

\section{Summary and Conclusions}

In this work, a new and comprehensive methodology to perform and analyse the GEB through the combination of experimental and theoretical tools is introduced, along with the adjustment methodologies required to ensure reli- 
able modelling results. The energy flows and interactions of the engine are divided in two points of view, the EGEB (mainly obtained from experimental information) which considers the flows through the engine assumed as a black box, and the IGEB (consist mainly of modelled terms), which includes the internal processes of the engine, considering detailed HT and mechanical losses processes to determine the energy degradation. To compare both points of view, comparable terms between EGEB and IGEB were defined, they are the total heat transfer $\left(\dot{Q}_{t o t}\right)$, the heat transfer to coolant $\left(\dot{Q}_{\text {cool }}\right)$ and oil $\left(\dot{Q}_{\text {oil }}\right)$. These terms are useful, one the one hand, to perform the calibration of the sub-models, and on the other hand, to assess the GEB tool performance.

As mentioned, the IGEB requires the development of some sub-models to determine the energy interactions which can not be measured. Moreover, the accurate determination of the HT requires a calibration of the correlations used to its determination. Thus, an integral calibration procedure, which includes the description of a HT model to the ports, a detailed mechanical losses model and a HT model between the oil and the coolant was presented.

The calibration started with the Engine characterization and the HT model calibration, obtaining accurate $C R$, $k_{d e f}, \Delta \alpha_{\mathrm{TDC}}, C_{w 1, m}, b$ and $C_{w 1, c}$ parameters, ensuring a proper HT estimation in the chamber, being this a key point for the GEB.

Once the GEB tool is completely calibrated, a brief uncertainty study was carried out. The most relevant findings are following commented:

- The maximum uncertainty observed in $\dot{Q}_{t o t}$ ranges between -2 and $-10 \% \dot{m}_{f} H_{v}$ at low engine speed at load; however, the main error is lower than $\pm 1 \% \dot{m}_{f} H_{v}$ in the complete engine map.

- The maximum uncertainty observed in $\dot{Q}_{\text {cool }}$ is about $5 \% \dot{m}_{f} H_{v}$ at $1000 \mathrm{rpm}$ and $25 \%$, but a lower mean uncertainty about $\pm 2 \% \dot{m}_{f} H_{v}$ is observed in the complete engine map.

- The maximum deviation of $\dot{Q}_{\text {oil }}$ is about $-1.5 \% \dot{m}_{f} H_{v}$ at low engine speed at load. However, an uncertainty lower than $1 \% \dot{m}_{f} H_{v}$ is observed for the engine map.

\section{Acknowledgments}

This work was partially funded by the Government of Spain through Project TRA2013-41348-R. In addition, the authors acknowledge that some equipment used in this work has been partially supported by FEDER project funds (FEDER-ICTS-2012-06), framed in the operational program of unique scientific and technical infrastructure of the Ministry of Science and Innovation of Spain. 


\section{References}

[1] S. Molina, C. Guardiola, J. Martín, D. García-Sarmiento, Development of a control-oriented model to optimise fuel consumption and NOX emissions in a DI Diesel engine, Applied Energy 119 (2014) 405-416. doi:10.1016/J.APENERGY.2014.01.021.

[2] B. Mohan, W. Yang, S. K. Chou, Fuel injection strategies for performance improvement and emissions reduction in compression ignition engines-A review, Renewable and Sustainable Energy Reviews 28 (2013) 664-676. doi:10.1016/j.rser.2013.08.051.

[3] S. Jaichandar, K. Annamalai, Combined impact of injection pressure and combustion chamber geometry on the performance of a biodiesel fueled diesel engine, Energy 55 (2013) 330-339. doi:10.1016/j.energy.2013.04.019.

[4] J. Benajes, J. Martín, R. Novella, K. Thein, Understanding the performance of the multiple injection gasoline partially premixed combustion concept implemented in a 2-Stroke high speed direct injection compression ignition engine, Applied Energy 161 (2016) 465-475. doi:10.1016/j.apenergy.2015.10.034.

[5] S. E. Iannuzzi, G. Valentino, Comparative behavior of gasoline-diesel/butanol-diesel blends and injection strategy management on performance and emissions of a light duty diesel engine, Energy 71 (2014) 321-331. doi:10.1016/j.energy.2014.04.065.

[6] M. Canakci, Combustion characteristics of a DI-HCCI gasoline engine running at different boost pressures, Fuel 96 (2012) $546-555$. doi:10.1016/j.fuel.2012.01.042.

[7] F. Perini, P. C. Miles, R. D. Reitz, A comprehensive modeling study of in-cylinder fluid flows in a high-swirl, light-duty optical diesel engine, Computers \& Fluids 105 (2014) 113-124. doi:10.1016/j.compfluid.2014.09.011.

[8] J. Benajes, R. Novella, D. De Lima, P. Tribotté, N. Quechon, P. Obernesser, V. Dugue, Analysis of the combustion process, pollutant emissions and efficiency of an innovative 2-stroke HSDI engine designed for automotive applications, Applied Thermal Engineering 58 (1-2) (2013) 181-193. doi:10.1016/j.applthermaleng.2013.03.050.

[9] R. Verschaeren, W. Schaepdryver, T. Serruys, M. Bastiaen, L. Vervaeke, S. Verhelst, Experimental study of NOx reduction on a medium speed heavy duty diesel engine by the application of EGR (exhaust gas recirculation) and Miller timing, Energy 76 (2014) 614-621. doi:10.1016/j.energy.2014.08.059.

[10] E. Sher, T. Bar-Kohany, Optimization of variable valve timing for maximizing performance of an unthrottled SI engine-a theoretical study, Energy 27 (2002) 757-775. doi:10.1016/S0360-5442(02)00022-1.

[11] C. Guardiola, J. López, J. Martín, D. García-Sarmiento, Semiempirical in-cylinder pressure based model for NOX prediction oriented to control applications, Applied Thermal Engineering 31 (12) (2011) 3275-3286. doi:10.1016/j.applthermaleng.2011.05.048.

[12] G. Karavalakis, D. Short, D. Vu, R. L. Russell, A. Asa-Awuku, H. Jung, K. C. Johnson, T. D. Durbin, The impact of ethanol and iso-butanol blends on gaseous and particulate emissions from two passenger cars equipped with spray-guided and wall-guided direct injection SI (spark ignition) engines, Energy 82 (2015) 168-179. doi:10.1016/j.energy.2015.01.023.

[13] V. Bermúdez, J. M. Luján, P. Piqueras, D. Campos, Pollutants emission and particle behavior in a pre-turbo aftertreatment light-duty diesel engine, Energy 66 (2014) 509-522. doi:10.1016/j.energy.2014.02.004.

[14] Regulation (EU) No 333/2014 of the European Parliament and of the Council of 11 March 2014 amending Regulation (EC) No 443/2009 to define the modalities for reaching the 2020 target to reduce $\mathrm{CO} 2$ emissions from new passenger cars, Official Journal of the European Union L103 Vol 57 (2014) 15-21.

[15] R. D. Burke, C. J. Brace, J. G. Hawley, I. Pegg, Review of the systems analysis of interactions between the thermal, lubricant, and combustion processes of diesel engines, Journal of Automobile Engineeringdoi:10.1243/09544070JAUTO1301.

[16] X. Tauzia, A. Maiboom, Experimental study of an automotive Diesel engine efficiency when running under stoichiometric conditions, Applied Energy 105 (2013) 116-124. doi:10.1016/j.apenergy.2012.12.034.

[17] I. Taymaz, An experimental study of energy balance in low heat rejection diesel engine, Energy 31 (2-3) (2006) 364-371. doi:10.1016/j.energy.2005.02.004.

[18] V. Macián, B. Tormos, V. Bermúdez, L. Ramírez, Assessment of the effect of low viscosity oils usage on a light duty diesel engine fuel consumption in stationary and transient conditions, Tribology International 79 (2014) 132-139. doi:10.1016/j.triboint.2014.06.003. 
[19] U. Morawitz, J. Mehring, L. Schramm, Benefits of Thermal Spray Coatings in Internal Combustion Engines, with Specific View on Friction Reduction and Thermal Management, SAE paper 2013-01-0292doi:10.4271/2013-01-0292.

[20] J. R. Serrano, P. Olmeda, A. Tiseira, L. M. García-Cuevas, A. Lefebvre, Theoretical and experimental study of mechanical losses in automotive turbochargers, Energy 55 (2013) 888-898. doi:10.1016/j.energy.2013.04.042.

[21] M. Abedin, H. Masjuki, M. Kalam, A. Sanjid, S. A. Rahman, B. Masum, Energy balance of internal combustion engines using alternative fuels, Renewable and Sustainable Energy Reviews 26 (2013) 20-33. doi:10.1016/j.rser.2013.05.049.

[22] P. Dimopoulos, C. Bach, P. Soltic, K. Boulouchos, Hydrogen-natural gas blends fuelling passenger car engines: Combustion, emissions and well-to-wheels assessment, International Journal of Hydrogen Energy 33 (23) (2008) 7224-7236. doi:10.1016/j.ijhydene.2008.07.012.

[23] L. A. Smith, W. H. Preston, G. Dowd, O. Taylor, K. M. Wilkinson, Application of a First Law Heat Balance Method to a Turbocharged Automotive Diesel Engine, SAE paper 2009-01-0244doi:doi:10.4271/2009-01-2744.

[24] O. Durgun, Z. Şahin, Theoretical investigation of heat balance in direct injection (DI) diesel engines for neat diesel fuel and gasoline fumigation, Energy Conversion and Management 50 (1) (2009) 43-51. doi:10.1016/j.enconman.2008.09.007.

[25] D. Jung, J. Yong, H. Choi, H. Song, K. Min, Analysis of engine temperature and energy flow in diesel engine using engine thermal management, Journal of Mechanical Science and Technology 27 (2) (2013) 583-592. doi:10.1007/s12206-012-1235-4.

[26] F. Caresana, M. Bilancia, C. Bartolini, Numerical method for assessing the potential of smart engine thermal management: Application to a medium-upper segment passenger car, Applied Thermal Engineering 31 (16) (2011) 3559-3568. doi:10.1016/j.applthermaleng.2011.07.017.

[27] L. Jarrier, J. C. Champoussin, R. Yu, D. Gentile, Warm-Up of a D.I. Diesel Engine : Experiment and Modeling, SAE paper 2000-01-0299.

[28] C. Lehner, G. Parker, O. Arici, J. Johnson, Design and Development of a Model Based Feedback Controlled Cooling System for Heavy Duty Diesel Truck Applications Using a Vehicle Engine Cooling System Simulation, SAE paper 2001-01-0336.

[29] S. Ruiz, P. Olmeda, J. Martín, R. Carreño, Improvement and application of a methodology to perform the Global Energy Balance in internal combustion engines. Part 2: Energy balance tool application, Article submitted to Energy.

[30] J. Heywood, Internal Combustion Engines Fundamentals, McGraw-Hill, New York, 1988.

[31] J. Benajes, P. Olmeda, J. Martín, R. Carreño, A new methodology for uncertainties characterization in combustion diagnosis and thermodynamic modelling, Applied Thermal Engineering 71 (2014) 389-399. doi:10.1016/j.applthermaleng.2014.07.010.

[32] F. Payri, J. Luján, J. Martín, A. Abbad, Digital signal processing of in-cylinder pressure for combustion diagnosis of internal combustion engines, Mechanical Systems and Signal Processing 24 (6) (2010) 1767-1784. doi:10.1016/j.ymssp.2009.12.011.

[33] F. Payri, P. Olmeda, C. Guardiola, J. Martín, Adaptive determination of cut-off frequencies for filtering the in-cylinder pressure in diesel engines combustion analysis, Applied Thermal Engineering 31 (14-15) (2011) 2869-2876. doi:10.1016/J.APPLTHERMALENG.2011.05.012.

[34] J. Tichý, G. Gautschi, Piezoelektrische Meßtechnik, Springer, Berlin, 1980.

[35] F. Payri, X. Margot, A. Gil, J. Martin, Computational Study of Heat Transfer to the Walls of a DI Diesel Engine, SAE Technical paper 2005-01-0210doi:10.4271/2005-01-0210.

[36] G. Woschni, A Universally Applicable Equation for the Instantaneous Heat Transfer Coefficient in the Internal Combustion Engine, SAE Technical Paper Series 670931.

[37] G. Woschni, Die Berechnung der Wandverluste und der thermischen Belastung der Bauteile von Dieselmotoren., MTZ 31 (12) (1970) 491499.

[38] A. Torregrosa, P. Olmeda, B. Degraeuwe, M. Reyes, A concise wall temperature model for DI Diesel engines, Applied Thermal Engineering 26 (11-12) (2006) 1320-1327. doi:10.1016/j.applthermaleng.2005.10.021.

[39] A. J. Torregrosa, P. Olmeda, J. Martín, C. Romero, A Tool for Predicting the Thermal Performance of a Diesel Engine, Heat Transfer Engineering 32 (10) (2011) 891-904. doi:10.1080/01457632.2011.548639.

[40] J. Martín, Diagnóstico de la combustión en motores de Diesel de inyección directa, Reverté, Barcelona, 2012.

[41] C. Depcik, D. Assanis, A Universal Heat Transfer Correlation for Intake and Exhaust Flows in an Spark-Ignition Internal Combustion Engine, SAE Technical Paper 2002-01-0372doi:10.4271/2002-01-0372.

[42] V. Dolz, Transmisión de calor en motores alternativos : aplicación al aprovechamiento energético de los gases de escape, Reverté, Barcelona, 
2011.

[43] E. N. Sieder, G. E. Tate, Heat Transfer and Pressure Drop of Liquids in Tubes, Industrial and Engineering Chemistry 28 (12). doi:10.1021/ie50324a027.

[44] D. Taraza, N. Henein, Friction Losses in Multi-Cylinder Diesel Engines, SAE paper 2000-01-0921.

[45] C. Taylor, Engine Tribology, Elsevier, 1997.

[46] M. Teodorescu, D. Taraza, N. Henein, W. Bryzik, Experimental Analysis of Dynamics and Friction in Valve Train Systems, SAE Technical Paper 2002-01-0484doi:10.4271/2002-01-0484.

[47] M. Teodorescu, D. Taraza, N. Henein, W. Bryzik, Simplified Elasto-Hydrodynamic Friction Model of the Cam-Tappet Contact, SAE Techinical Paper 2003-01-0985doi:10.4271/2003-01-0985.

[48] J. Guo, W. Zhang, D. Zou, Investigation of dynamic characteristics of a valve train system, Mechanism and Machine Theory 46 (12) (2011) 1950-1969. doi:10.1016/j.mechmachtheory.2011.07.014.

[49] N. Nayak, P. Lakshminarayanan, M. Babu, A. Dani, Predictions of cam follower wear in diesel engines, Wear 260 (1-2) (2006) $181-192$. doi:10.1016/j.wear.2005.02.022.

[50] D. A. Kouremenos, C. D. Rakopoulos, D. T. Hountalas, T. K. Zannis, Development of a Detailed Friction Model to Predict Mechanical Losses at Elevated Maximum Combustion Pressures, SAE paper 2001-01-0333.

[51] A. Comfort, An Introduction to Heavy-Duty Diesel Engine Frictional Losses And Lubricant Properties Affecting Fuel Economy - Part I, SAE Technical Paper Series 2003-01-3225. 
Table 1: Tested Engine technical data

\begin{tabular}{ll}
\hline Cylinders & 4 in-line \\
Strokes & 4 \\
Bore & $75 \mathrm{~mm}$ \\
Stroke & $88 \mathrm{~mm}$ \\
Unitary displacement & $390 \mathrm{~cm} 3$ \\
Total displacement & $1560 \mathrm{~cm} 3$ \\
Compression ratio & $16: 1$ \\
Air management & Turbocharged \\
Maximum power & $82 \mathrm{~kW}$ at $3600 \mathrm{rpm}$ \\
Maximum torque & $270 \mathrm{Nm}$ at $1750 \mathrm{rpm}$ \\
Cycle & Diesel \\
Injection & Common rail \\
\hline
\end{tabular}

Table 2: Test cell instrumentation

\begin{tabular}{ll} 
Variable & Equipment \\
\hline Cylinder pressure & AVL GH13P \\
Amplifier & Kistler 5011B \\
Speed and Torque control & SIEMENS Dynamometer \\
Air mass flow & Sensiflow \\
Fuel mass flow & AVL 733S Fuel meter \\
Blow-by mass flow & AVL blow-by Meter \\
Temperature & K-type Thermocouples and RTD \\
Mean pressure & Kistler Piezo-resistive Pressure Transmitters \\
Gases analysis & Horiba mexa \\
Coolant flow & Krohne 4010 Optiflux \\
Oil exchanger cooling & Isoil MS500 \\
Fuel exchanger cooling & Yoko AdmagAE208MG \\
Turbo oil mass flow & Krohne Optimass 3050C \\
\hline
\end{tabular}


Table 3: Measurement set

a) motoring

\begin{tabular}{lccccc} 
Speed (RPM) & Load $(\%)$ & $T_{\text {cool }}\left({ }^{\circ} \mathrm{C}\right)$ & $T_{\text {oil }}\left({ }^{\circ} \mathrm{C}\right)$ & $p_{a d m}(\mathrm{bar})$ & $p_{\text {exh }}$ (bar) \\
\hline 1000 & 0 & 55 & 60 & 1 & 1,2 \\
1500 & 0 & 55 & 65 & 1 & 1,5 \\
2000 & 0 & 55 & 65 & 1 & 1,5 \\
2500 & 0 & 55 & 65 & 1 & 1,7 \\
3000 & 0 & 55 & 68 & 1 & 1,5 \\
3500 & 0 & 55 & 68 & 1 & 1,7 \\
4000 & 0 & 55 & 73 & 1 & 2,1
\end{tabular}

b) combustion

\begin{tabular}{lccccc} 
Speed (RPM) & Load $(\%)$ & $T_{\text {cool }}\left({ }^{\circ} \mathrm{C}\right)$ & $T_{\text {oil }}\left({ }^{\circ} \mathrm{C}\right)$ & $p_{a d m}(\mathrm{bar})$ & $p_{\text {exh }}(\mathrm{bar})$ \\
\hline 1000 & $25-100$ & 85 & 90 & $1-1,3$ & $1-1,6$ \\
1500 & $25-100$ & 85 & $90-110$ & $1-2$ & $1,2-2,2$ \\
2000 & $25-100$ & 85 & $90-113$ & $1,2-2,5$ & $1,3-2,6$ \\
2500 & $25-100$ & 85 & $90-120$ & $1,4-2,6$ & $1,7-2,7$ \\
3000 & $25-100$ & 85 & $95-120$ & $1,5-2,6$ & $1,8-2,9$ \\
3500 & $25-100$ & 85 & $100-125$ & $1,6-2,5$ & $1,9-3$ \\
4000 & $25-100$ & 85 & $100-125$ & $1,6-2,3$ & $2-3$
\end{tabular}

Table 4: Results of Engine characterization and calibration of HT to chamber walls

\begin{tabular}{lc|lc}
\multicolumn{2}{c|}{ Motoring } & \multicolumn{2}{c}{ Combustion } \\
\hline$C_{W 1, m}$ & 2,3 & $C_{W 1, c}$ & 3,99 \\
$\mathrm{CR}$ & $15,9: 1$ & $b$ & 0,7 \\
$k_{d e f}$ & 1,29 & $C_{2}$ & 0,0012 \\
$\Delta \alpha_{\mathrm{TDC}}$ & 369,9 & &
\end{tabular}


Table 5: HT to the ports comparison between the intake and exhaust ports

Operating point Intake port Exhaust port (closed cycle) Exhaust port (open cycle)

\begin{tabular}{llll} 
Speed/load & {$[\mathrm{kW}]$} & {$[\mathrm{kW}]$} & {$[\mathrm{kW}]$} \\
\hline $1000 / 25$ & $-0,008$ & 0,017 & 0,252 \\
$1000 / 100$ & $-0,027$ & 0,074 & 1,009 \\
$2000 / 50$ & $-0,037$ & 0,175 & 1,746 \\
$4000 / 25$ & $-0,088$ & 0,124 & 1,098 \\
$4000 / 100$ & $-0,160$ & 0,374 & 2,969
\end{tabular}

Table 6: Auxiliary and friction adjusted calibration constants

\begin{tabular}{|c|c|c|c|c|c|c|c|}
\hline \multicolumn{2}{|c|}{ Coolant pump } & \multicolumn{2}{|r|}{ Oil pump } & \multicolumn{2}{|r|}{ Fuel pump } & \multicolumn{2}{|r|}{ Friction } \\
\hline$k 1_{\text {cool }}$ & $5,14 \times 10^{-5} \frac{\mathrm{bar}}{(\mathrm{l} / \mathrm{min})^{2}}$ & $k_{\text {oil }}$ & $7,9 \times 10^{-3} \frac{l / m i n}{r p m}$ & $k 1_{f}$ & $3,43 \times 10^{-9} \frac{\mathrm{m}^{3} / \mathrm{s}}{(\mathrm{g} / \mathrm{s})^{0.6}}$ & $k 1_{\text {pis }}$ & 0,498 \\
\hline$k 2_{\text {cool }}$ & $5,51 \times 10^{-2} \frac{l / m i n}{r p m}$ & $\eta_{\text {oil }}$ & $90 \%$ & $k 2_{f}$ & 0,6 & $k 2_{\text {pis }}$ & $2,28 \times 10^{-3} \mathrm{rpm}^{-1}$ \\
\hline$\eta_{\text {cool }}$ & $85 \%$ & & & $\eta_{f}$ & $85-90 \%$ & $k_{\text {bear }}$ & 3,9 \\
\hline & & & & & & $k_{\text {valv }}$ & 2,5 \\
\hline
\end{tabular}




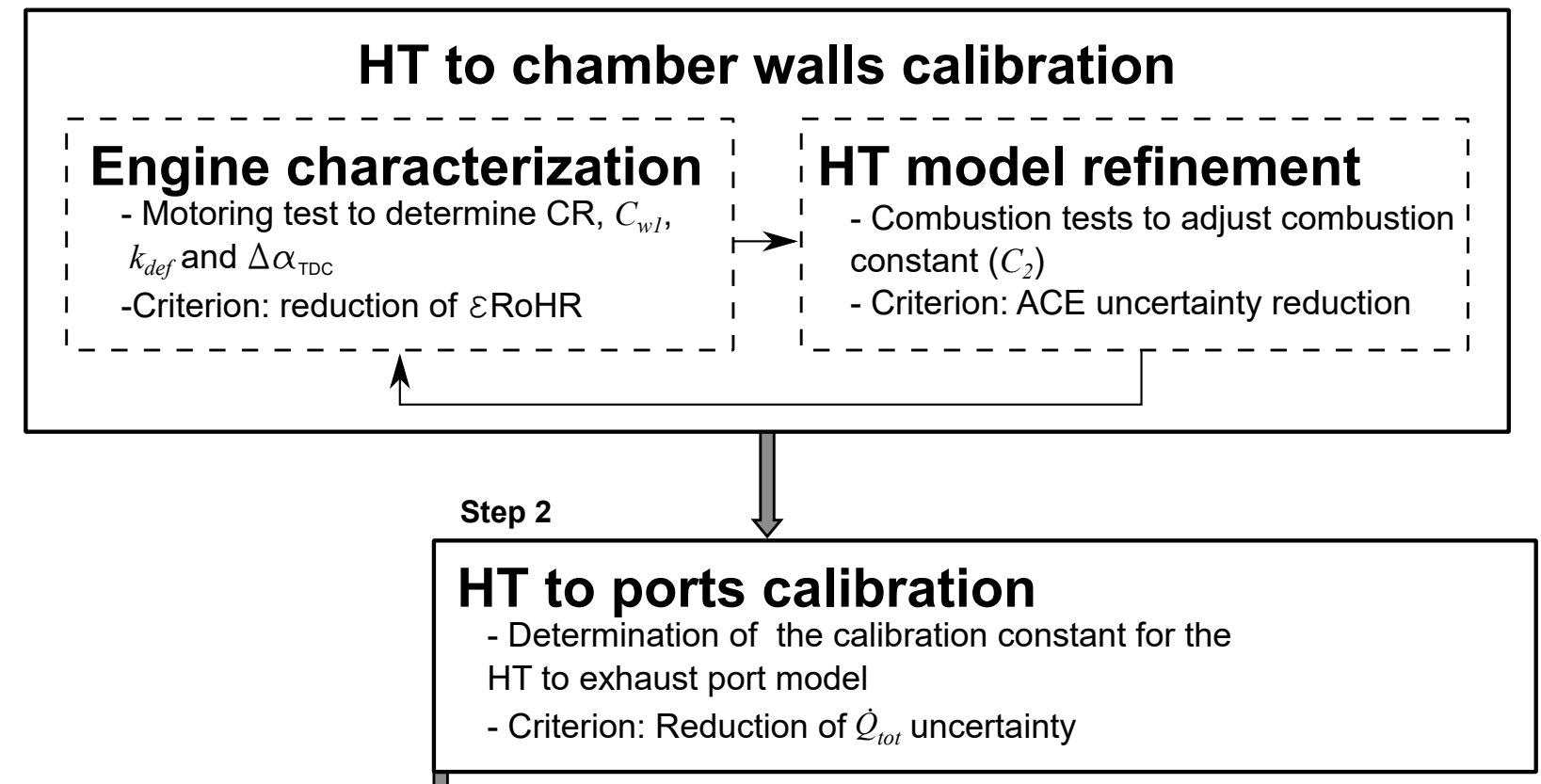

Step 3

\section{Mechanical losses calibration}

- Calibration of the constants in the engine map

-Criterion: $N_{f r}+N_{a}$ uncertainty reduction

Step 4

\section{HT from oil to coolant calibration}

- Criterion: Reduction of $\dot{Q}_{\text {oil }}$ uncertainty

Figure 1: Calibration of engine heat transfer 


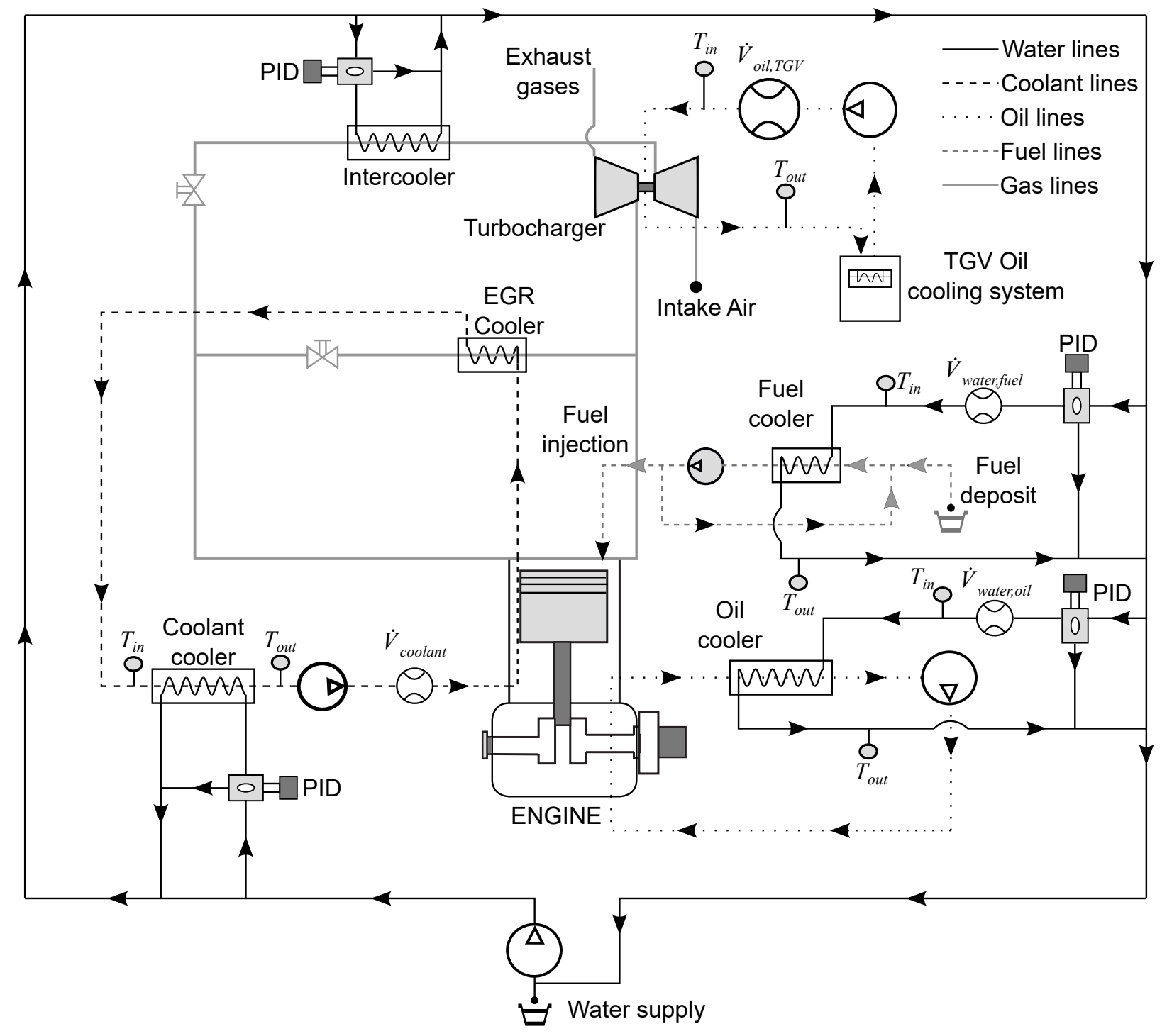

Figure 2: Test cell layout 


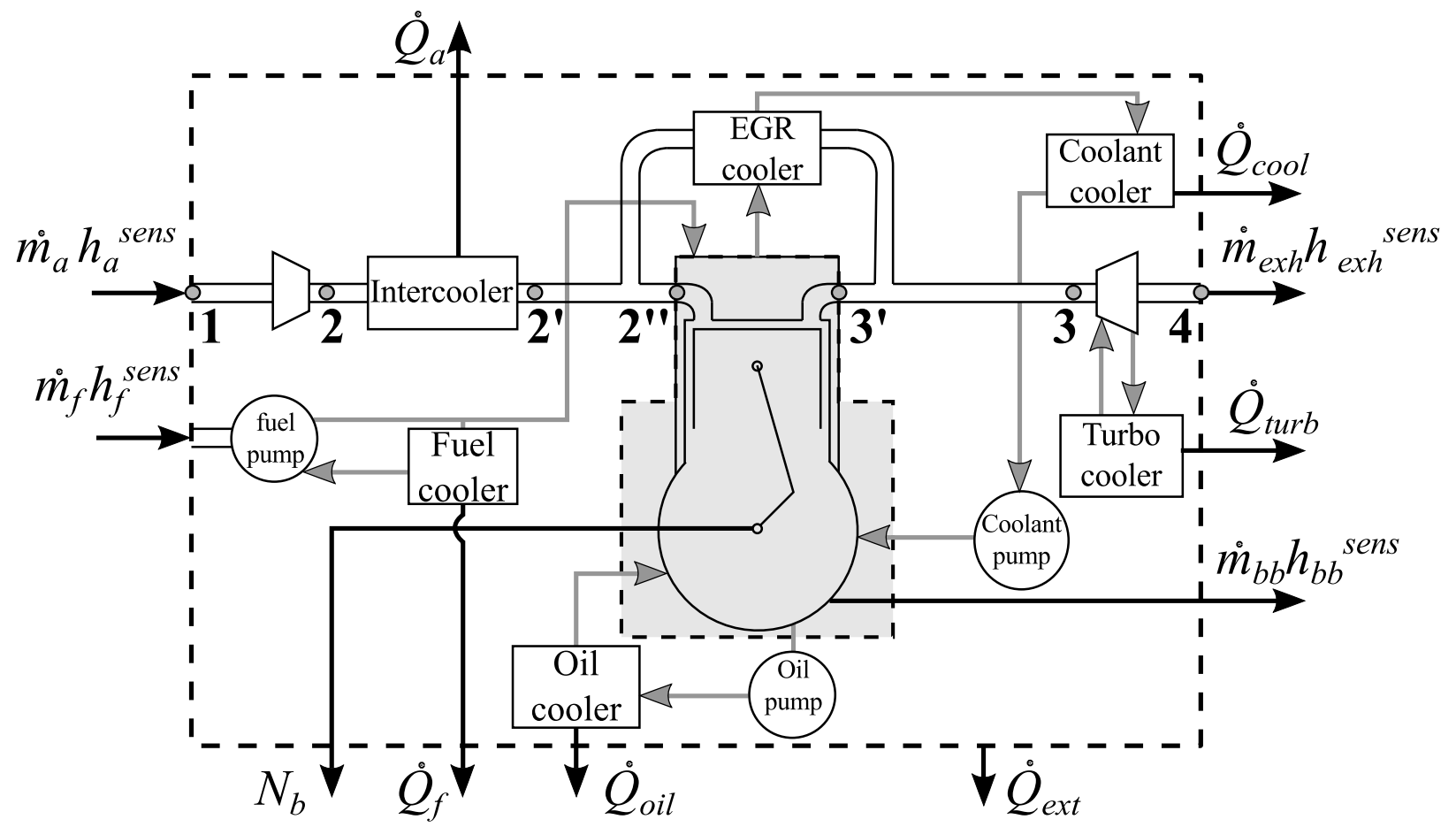

Figure 3: Engine energy scheme

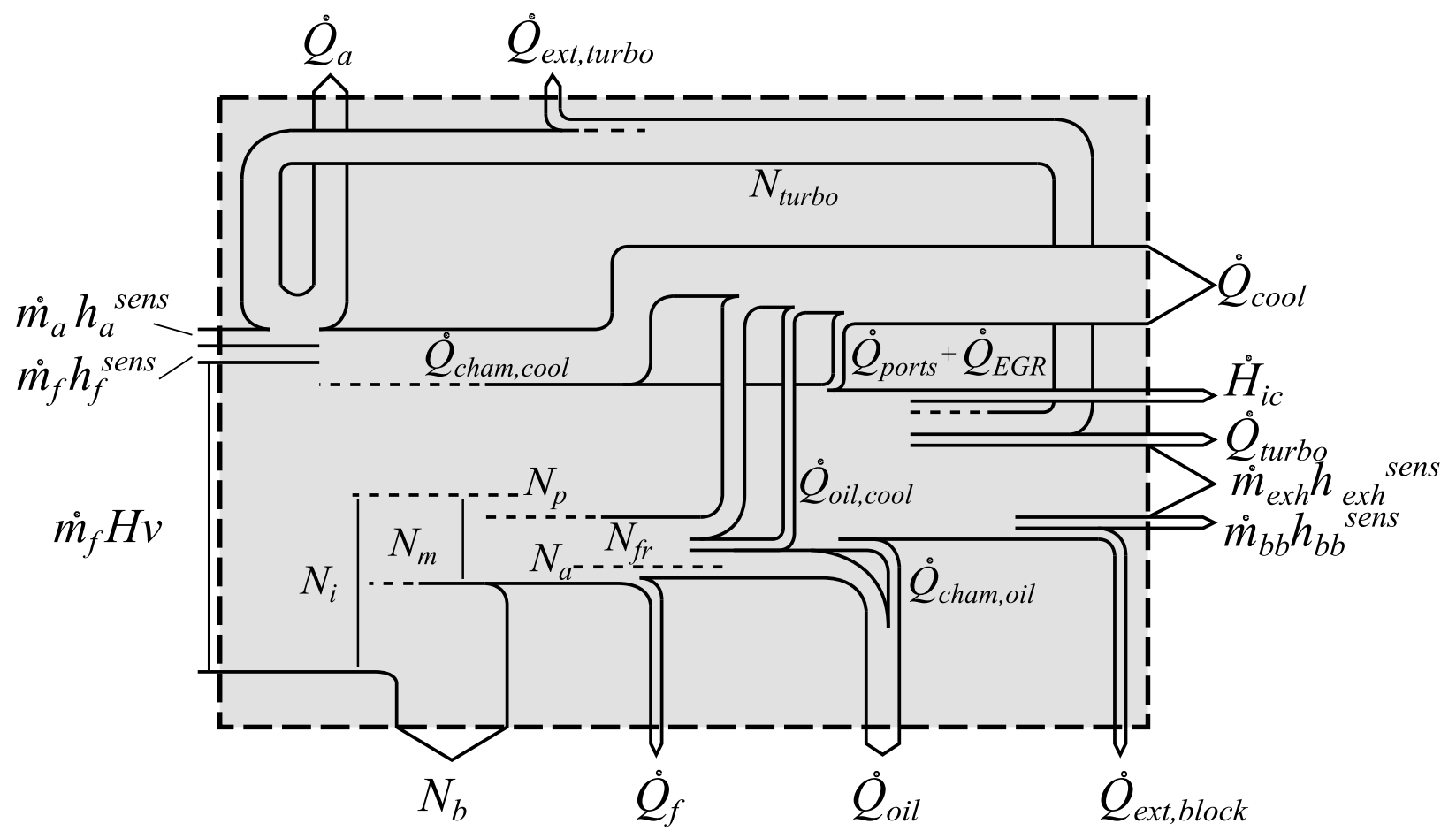

Figure 4: Global energy balance scheme 


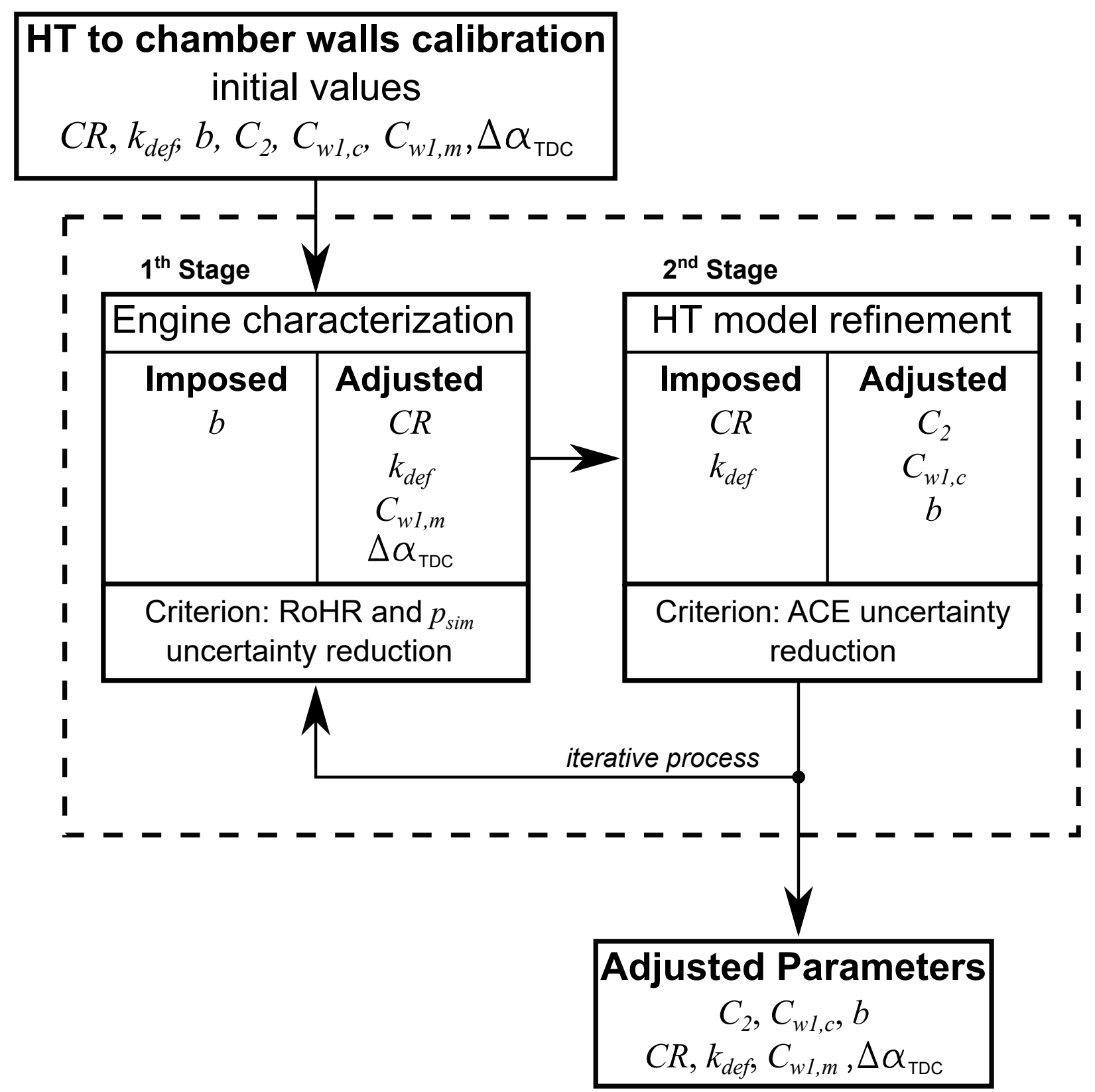

Figure 5: HT adjustment procedure 


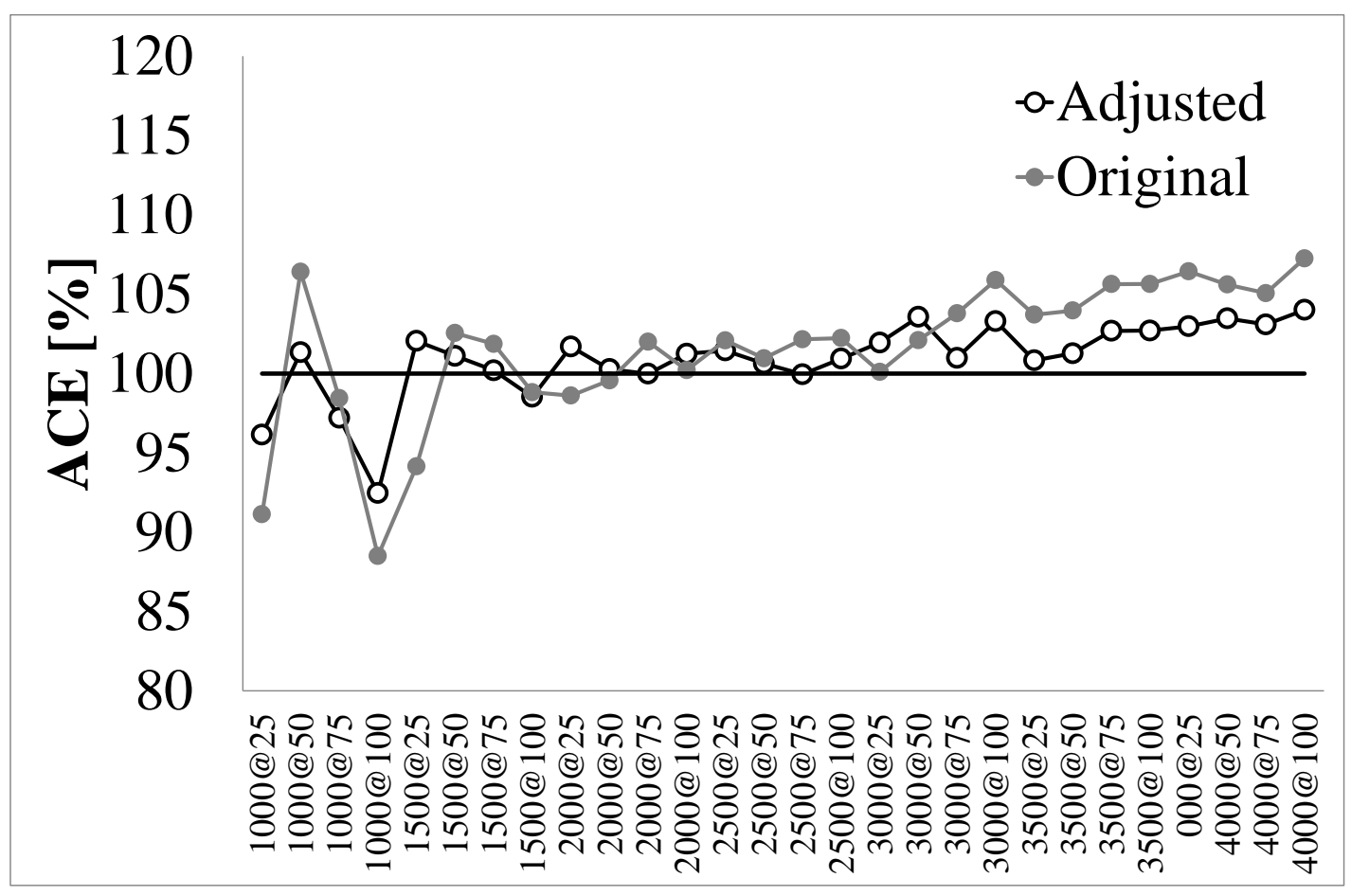

Figure 6: Apparent combustion efficiency 


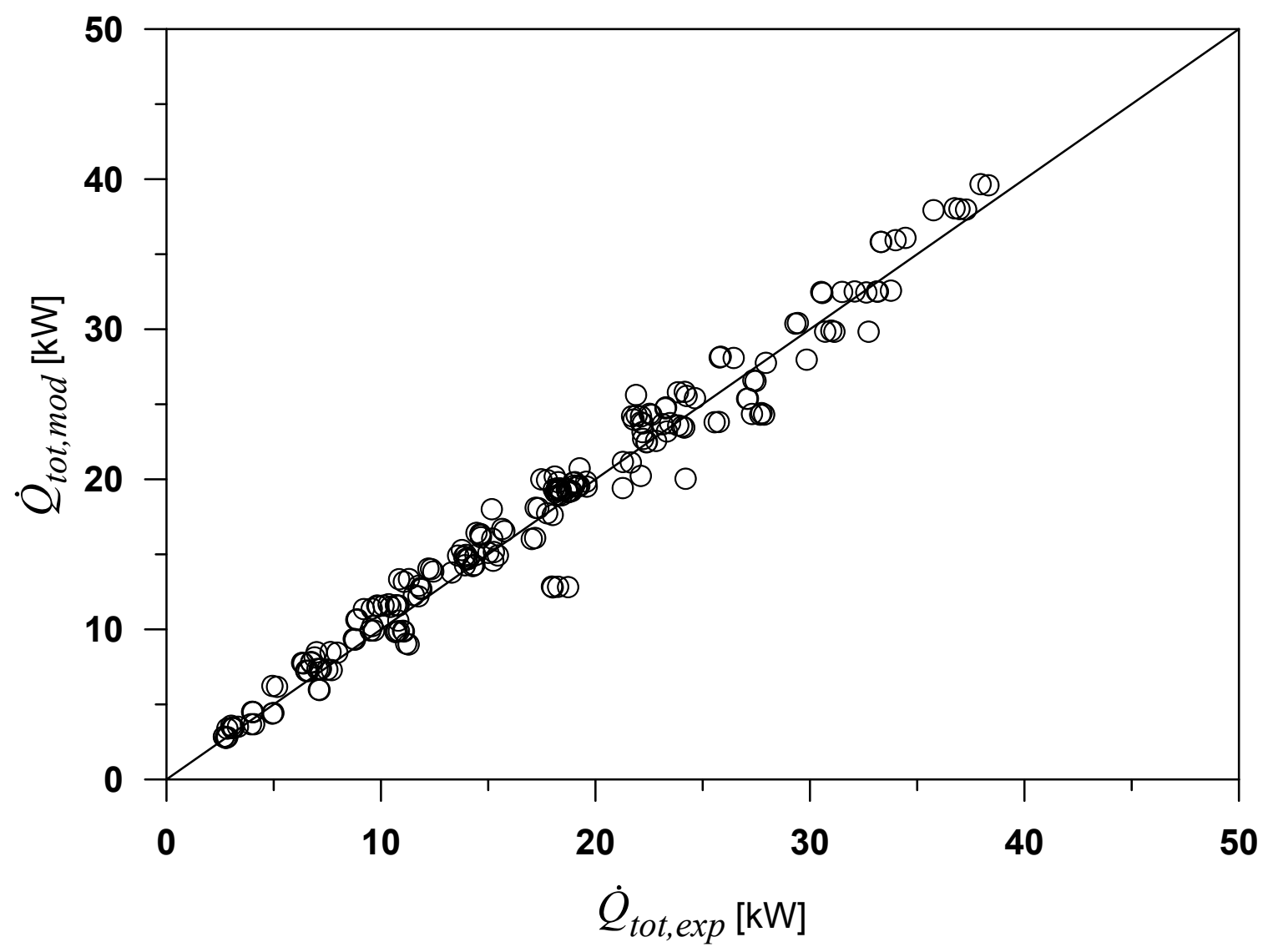

Figure 7: Total heat transfer 

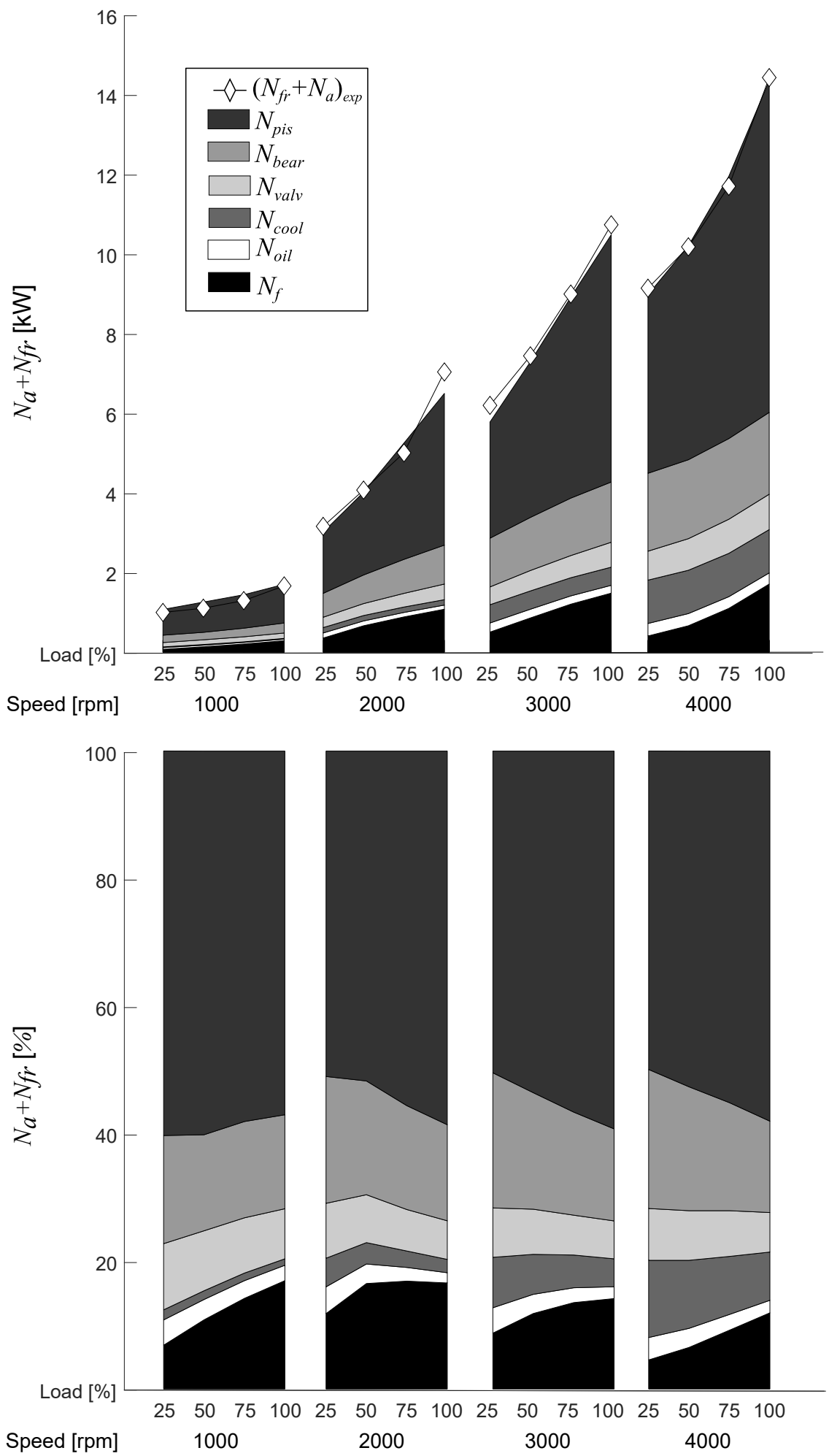

Figure 8: Auxiliary and friction 


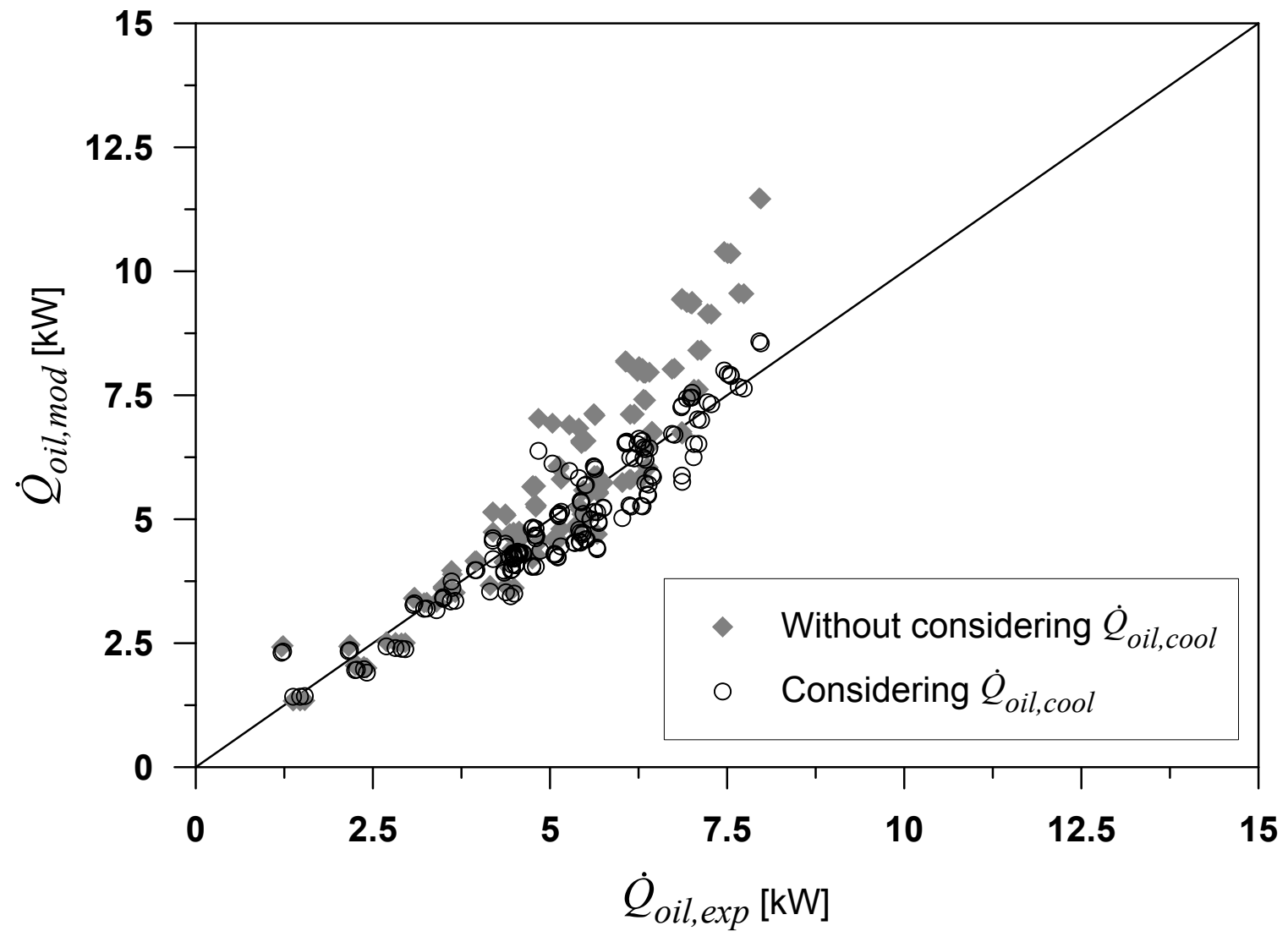

Figure 9: Heat transfer to the oil 


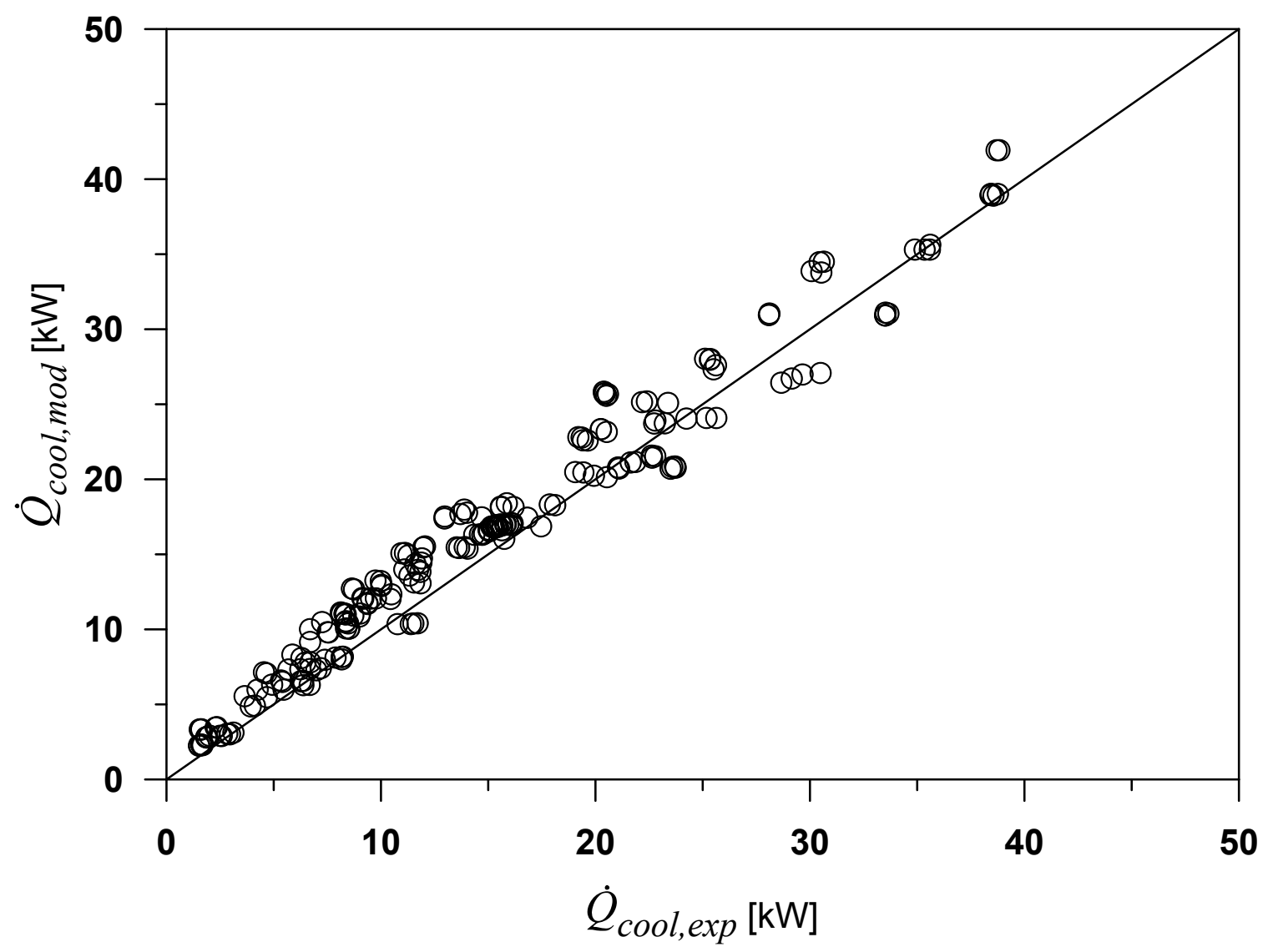

Figure 10: Heat transfer to the coolant 


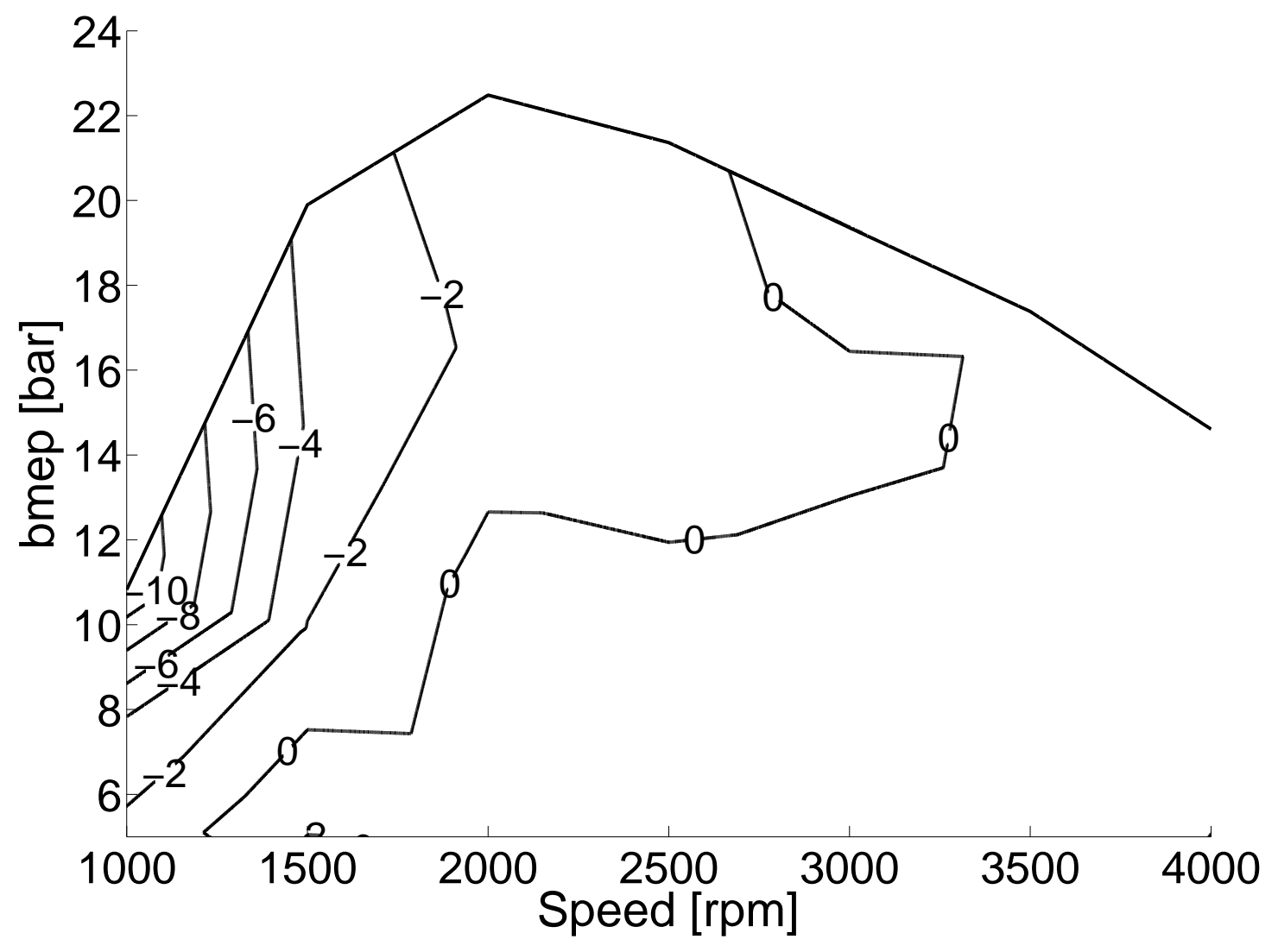

Figure 11: Difference between $\dot{Q}_{t o t, m o d}$ and $\dot{Q}_{t o t, e x p} \mathrm{HT}$ in $\dot{m}_{f} H_{v}$ 


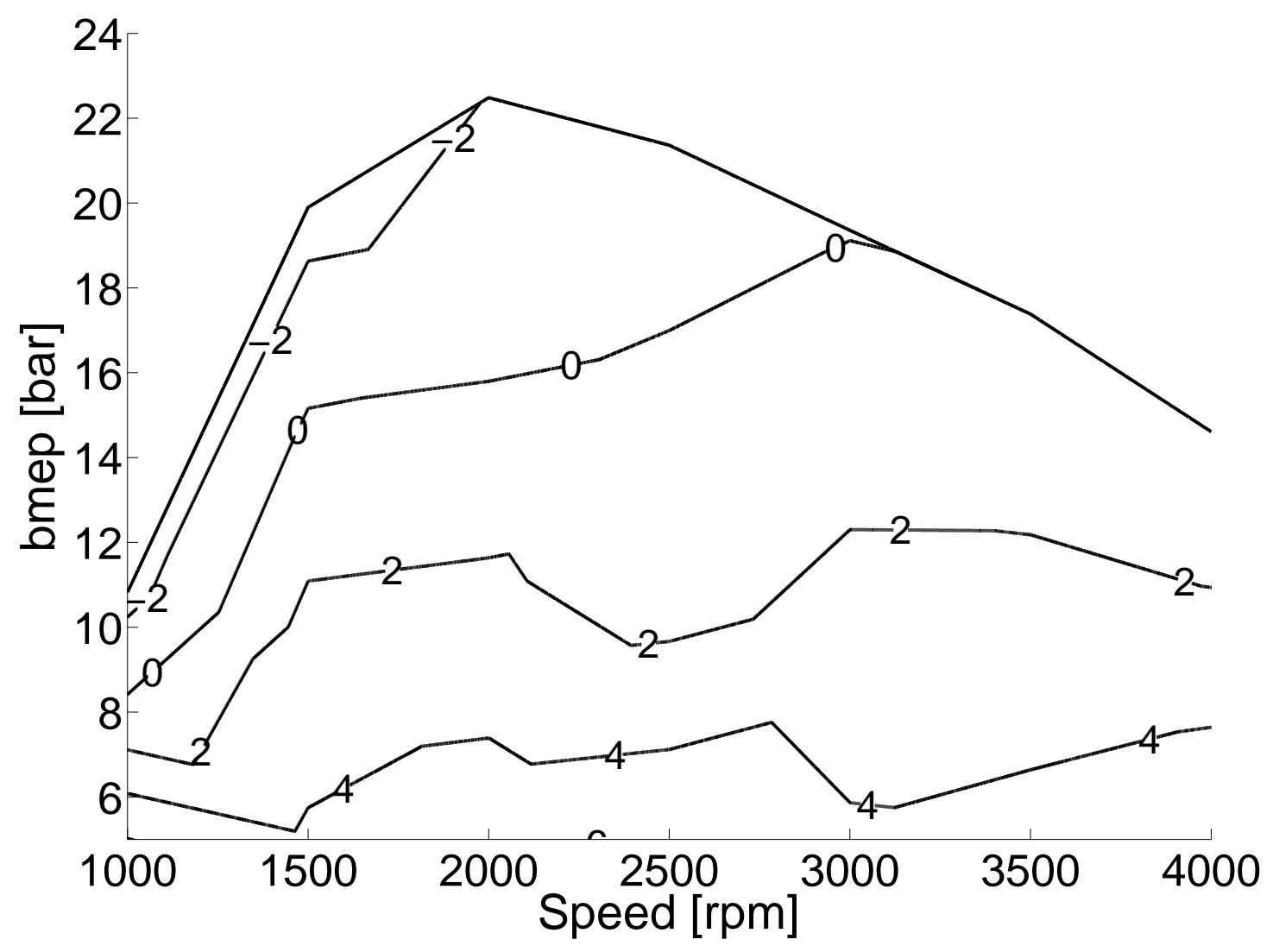

Figure 12: Difference between $\dot{Q}_{c o o l, m o d}$ and $\dot{Q}_{c o o l, e x p} \mathrm{HT}$ in $\dot{m}_{f} H_{v}$ 


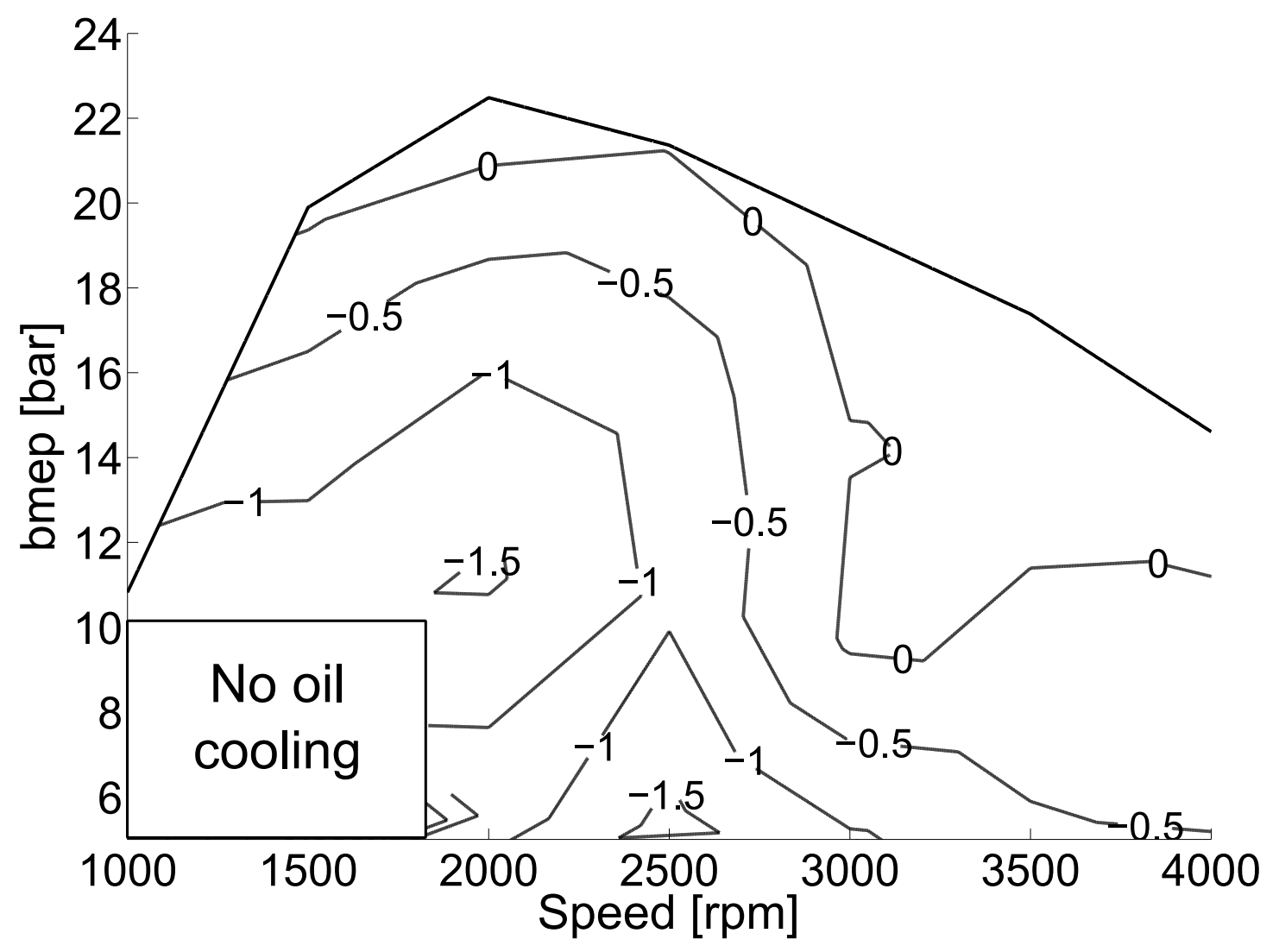

Figure 13: Difference between $\dot{Q}_{\text {oil,mod }}$ and $\dot{Q}_{\text {oil,exp }} \mathrm{HT}$ in $\dot{m}_{f} H_{v}$ 